\title{
The Effect of the MNRI Method on Neurotransmitter Biomarkers of Individuals with Neurodevelopmental Disorders
}

\author{
Clayton Bell1, Jordan Whitney², Trina Deiss ${ }^{3}$, Tatiana Tatarinova4, Lorri Franckle5, \\ Susan Beaven ${ }^{6}$, Jeffrey Davis ${ }^{7}$
}

${ }^{1}$ Department of Family Medicine, University of Tennessee Medical Center, Knoxville, TN, USA

${ }^{2} 3 \mathrm{M}$ Co., Minneapolis, MN, USA

${ }^{3}$ United Front Foundation, Minneapolis, MN, USA

${ }^{4}$ University of La Verne, La Verne, CA, USA

${ }^{5}$ Laser Health, Orlando, FL, USA

${ }^{6}$ St. Petersburg Free Clinic, St. Petersburg, FL, USA

${ }^{7}$ Prairie Health and Wellness, Wichita, KS, USA

Email: saverkamp@sbcglobal.net

How to cite this paper: Bell, C., Whitney, J., Deiss, T., Tatarinova, T., Franckle, L., Beaven, S. and Davis, J. (2019) The Effect of the MNRI Method on Neurotransmitter Biomarkers of Individuals with Neurodevelopmental Disorders. Neuroscience \& Medicine, 10, 292-321.

https://doi.org/10.4236/nm.2019.103022

Received: July 15, 2019

Accepted: September 21, 2019

Published: September 24, 2019

Copyright $\odot 2019$ by author(s) and Scientific Research Publishing Inc. This work is licensed under the Creative Commons Attribution International License (CC BY 4.0).

http://creativecommons.org/licenses/by/4.0/

\begin{abstract}
Introduction: The MNRI (Masgutova Neurosensorimotor Reflex Integration) method was developed in 1989 in Russia and has spread world-wide to treat individuals with certain types reflex development deficits, behavior disorders, disorders of speech or language development, and learning disabilities. MNRI is based on techniques called "repatterning" or remodulation, meaning re-education, recoding the reflex nerve pathways specific for dynamic and postural reflex schemes. Objectives: Repatterning activates the extra pyramidal nervous system responsible for automatic mechanisms and processes, the extension of links between neurons, the growth of neural nets, myelination, and the creation of new nerve routing. This potential result was tested utilizing urinary measurements of the following neurotransmitters: epinephrine, norepinephrine, dopamine, DOPAC, serotonin, 5-HIAA, glycine, taurine, GABA, glutamate, PEA, and histamine. Methods: Neurological impact of the Masgutova Neurosensorimotor Reflex Method on the magnitude of changes in neurotransmitters was assessed by an external controlled and double-blind method using patients from one of the four diagnosis groups: 1) global developmental disorders; 2) cerebral palsy, Traumatic Brain Injury (TBI), Acute Brain Injury (ABI), and seizures; 3) ADD/ADHD; and 4) anxiety disorders. Results: The post-MNRI results in participants show a tendency for regulation of the above neurotransmitters resulting in their calming down, decrease of hypervigilance, stress resilience increase, improvements in behavioral and emotional regulation, positive emotions, and cognitive pro-
\end{abstract}


cesses control. Conclusion: The application of the Masgutova Neurosensorimotor Reflex Method as a therapy modality offers a novelty paradigm for the treatment using neuro- and immune-modulation technologies presenting a non-pharmaceutical approach, based on use of neurosensorimotor reflex circuit concept.

\section{Keywords}

Neurotransmitters, Masgutova Neurosensorimotor Reflex Method (MNRI), Sensory-Motor Reflex Integration, Immunology, Global Developmental Disorders, Cerebral Palsy, Traumatic Brain Injury (TBI), Acute Brain Injury (ABI), Seizures, ADD/ADHD, and Anxiety Disorders

\section{Introduction}

Many interventions addressing developmental disorders in the medical sciences, psychology, and pediatric developmental programs use an interdisciplinary approach. The intervention used in this study with the four specific groups of participants differs from the traditional forms of medical support (medications, surgical procedures, orthotics, etc.), PT (physiotherapy), OT (occupational therapy), SP (speech therapy), cognitive-behavioral therapy, neurofeedback [1] massage therapy, hydrotherapy, dietary advice, alternative treatments such as Bobath Neuro-Developmental Techniques [2] Doman-Delacato [3] Vojta [4], Respiratory Therapy, as well as many others.

Masgutova Neurosensorimotor Reflex Method (MNRI) addresses the neurosensorimotor aspect of early sensory-motor patterns and reflexes to support sensory-motor integration and neurodevelopment of children and adults with neurodeficits and learning challenges: CP, TBI [5] [6] [7] [8], ASD [9] [10] Down syndrome [11] [12] [13] [14] [15] and other [16] [17]. MNRI therapy meets the ever-increasing demands for neurorehabilitation of individuals with impaired sensorimotor functions due to damage or dysfunctions in central nervous systems. Previous studies of the MNRI Method and its different sub-programs demonstrated a positive effect on immune markers [13] [18] [19], neurophysiological functions [7] [8] and different developmental aspects including the regulation of behavior and emotions, language, and communication [9] [17] [20] [21].

This paper presents a study of the effectiveness of MNRI therapy using neurotransmitter analysis. The aim was to investigate whether the neurotransmitters markers improve as a result of MNRI Reflex Integration treatment modality for individuals with global developmental disorders, cerebral palsy, traumatic brain injury (TBI), acute brain injury (ABI), seizures, $\mathrm{ADD} / \mathrm{ADHD}$, and anxiety disorders.

The MNRI method was developed in 1989 in Russia and further elaborated in Eastern Europe to treat individuals with certain types of sensorimotor or reflex 
development deficits, behavior disorders, disorders of speech or language development, and learning disabilities. It was introduced to the USA in 1996 and has gradually become adopted in many other countries. Clinical observations showed that MNRI facilitates the neurodevelopment in individuals having various neurological deficits and enables them to reroute and improve their early movements, reflex patterns, coordination systems, and skills to enable more optimal functioning, development, and learning [5] [6] [7] [8] [9] [11] [13]. The MNRI therapy program is based on the theory that impaired reflex circuits can be reconstructed and re-integrated, which involves awakening the genetic sensorimotor memory in individuals even with severe diagnosis, for example, with $\mathrm{CP}$ and brain damage [5] [6]. MNRI is an evidence and research-based system of a therapeutic program oriented to analyze the effect of the MNRI reflex integration techniques for neurosensorimotor-cognitive development of children and adults with neurodeficits and learning problems [22]. The studies were conducted by Dr. S. Masgutova and her team and scientific colleagues from different countries between 1989 and 2016 [22].

MNRI is based on exercises and techniques called "repatterning", meaning re-education, recoding, rerouting of and paving the reflex nerve pathways specific for dynamic and postural reflex schemes (e.g., Babinski, Automatic Gait, Bauer Crawling, Hands Grasp, and others) (Reflexes: Portal to Neurodevelopment and Learning 2015). The stimulation of reflex pathways is aimed at strengthening and stabilizing the traces of genetic sensory-motor memory and activation of innate defensive mechanisms of the body's brain "alarm" system (HPA-stress axis or "hypothalamus- > pituitary gland- > adrenals" cycle activation) in times of stress or danger [23]. MNRI exercises stimulate innate neuro-regulation mechanisms and resilience in the stress and immune systems [8] [9] [24]. Repatterning activates the extra pyramidal nerve system (peripheral nerves, spinal cord, brain stem, and diencephalon) responsible for automatic mechanisms and processes, the extension of links between neurons, the growth of neural nets, myelination, and the creation of new nerve routing, as described by Sechenov [25] [26], Pavlov [27], Anokhin [28], Haines [29], Virella [30].

There are various ways to assess neurotransmitters in the body. The three most common ways to achieve this include:

1) The commonly accepted method of testing the neurotransmitters is cerebral spinal fluid (CSF). While this approach does accurately reflect what is happening with the central nervous system transmitter levels, there are considerable drawbacks to utilizing this method in an educational facility for and non-medical purposes. Collection of the spinal fluid can also create stress in the participant, therefore increasing levels of key neurotransmitters such as norepinephrine and epinephrine. Another drawback to CSF usage is that there is yet to be established optimal ranges for neurotransmitters, therefore it is difficult to have consistent and relevant interpretation.

2) Another option for testing is by venipuncture. This method also increases 
stress levels and therefore has the potential of altering the true neurotransmitter levels. Blood samples would require special handling to maintain the fluid's integrity.

3) Given the invasiveness and instability issues of methods (1) and (2), urine testing provides the most optimal alternative.

For nearly 60 years, studies have utilized urinary measurements of neurotransmitters and neurotransmitter metabolites (Marc, et al. 2010). Since the 1950 s, increased urinary excretion of dopamine $(D A)$, norepinephrine $(N E)$, and epinephrine $(E)$, the three naturally occurring catecholamines, has been used to diagnose pheochromocytoma. Early days concerns about the limitations of urinalysis for neurotransmitters, were alleviated by development of fluorometric methods. High-Performance Liquid Chromatography (HPLC) methodology has expanded parameters of even greater specificity and sensitivity, allowing an even wider span of clinical application [31] [32] [33]. Lynn-Bullock examined the effects of oral ingestion of the serotonin substrate (5-hydroxytryptophan (5-HTP)) on specific brain regions in rats [34]. Serotonin is a monoamine neurotransmitter and is implicated in many physiological and behavioral functions including: affect, aggression, appetite, cognition, emesis, endocrine function, gastrointestinal function, motor function, neurotropism, perception, sensory function, sex, sleep, and vascular function [34] [35]. Serotonin levels were measured using brain tissue immunoreactivity and urinalysis and observed maximum serotonin immunoreactivity in the serotonergic dorsal raphe nucleus within $2 \mathrm{~h}$ of 5-HTP administration. Urinary analysis of serotonin, 5-HTP, and 5-hydroxyindolacetic acid (5-HIAA), a serotonin metabolite, had parallel changes in immunoreactivity to the dorsal raphe nucleus, demonstrating a positive correlation between CNS serotonergic activity and urinary serotonin levels [35] [36].

Studies have further determined that those struggling with depression, $A D D$, and $A D H D$ have a direct correlation to neurotransmitters in the CNS and the urine. There are several reasons preventing the use of urinary neurotransmitter levels as a sole diagnostic tool. However, the utility of urinary neurotransmitter levels as indicators and biomarkers to gauge the realm of impact and treatment is unquestionable [37]. Clinicians are already utilizing urinary histamine markers as an accurate assessment tool and treatment directive. Studies have also demonstrated a direct correlation between neurotransmitter levels and acute PTSD in children [38].

This manuscript focused on the testing of the following neurotransmitters: epinephrine (1), norepinephrine (2), dopamine (3), DOPAC (4), serotonin (5), 5-HIAA (6), glycine (7), taurine (8), GABA (9), glutamate (10), PEA (11), and histamine (12).

Some of the studied neurotransmitters are related biochemically: $5 H I A A$ is a metabolite of serotonin, and DOPAC is a metabolite of dopamine. The neurotransmitters can be divided into two categories by: inhibitory vs. excitatory. This classification is complicated, since transmission of neurotransmitters is a complex system and any neurotransmitter can have a secondary function. For in- 
stance, $G A B A$ synapses are typically assumed to be inhibitory, however inhibitory and excitatory $G A B A$ connections coexist in the cerebellar interneuron network. Psychoneuroimmunology studies have shown that the central nervous system has complex interactions with the endocrine and the immune systems. Although the mechanisms of these interactions are not fully understood, it is known that stress can induce modulation of the immune system, acting via the hypothalamic-pituitary-adrenal circuit and the sympathetic-adrenal medullary axes [23] [29] [30] [39].

Immune and central nervous systems are integrative and interdependently maintaining. The central nervous system modulates the immune system by hardwiring sympathetic and parasympathetic nerves (autonomic nervous system) to lymphoid organs. Neuroendocrine hormones (such as corticotrophin-releasing hormone or substance $\mathrm{P}$ ) regulate the cytokine balance. The immune system, in turn, affects brain activity including inhibition-excitation processes, as well as sleep, and body temperature. Working in this highly reciprocal manner the immune-nervous system creates a unique functional and anatomical link for the organism to act at multiple levels [29] [39]. Stress can disrupt interaction between the nervous and immune system [39].

There are three major forms of neurotransmitters functioning in a human organism, all of which communicate via signals targeting specific cells. These are: acetylcholine neurotransmitter, biogenic amines, and amino acids. Below we present a general overview of the analyzed transmitters.

Gamma Amino Butyric Acid (GABA) is the major inhibiting or calming transmitter in a human organism. The role of $G A B A$ is to inhibit or reduce the activity of the neurons or nerve cells, and the calming effect is achieved by restricting neuroelectric activity [40]. The body relies on $G A B A$ to reduce anxiety. The activity of $G A B A$ is increased during sleep, making $G A B A$ responsible for setting the circadian rhythms in humans. Other functions are impacted by $G A B A$, for example, female hormonal cycles are affected by circadian rhythm. $G A B A$ is prominent in the hippocampus, this part of the brain is responsible for memory formation, by allowing the brain to reconfigure neural connections [40] [41]. Excess of $G A B A$ may lead to depression or apathy; low levels of $G A B A$ are known to affect sleep. There is also a potential influence of $G A B A$ on immunity and physiology wellness [42].

Glutamate is an excitatory neurotransmitter that enhances signal transduction; it is tied to learning and memory; it is also one of the most common neurotransmitters: there is more glutamate in the brain than any other amino acid. Tissue extracted from the brain contains 5 - 15 mmol glutamate per $\mathrm{kg}$ [43]. Glutamate is not only involved in cognitive functions, but also learning function. Being an amino acid, it has a role in metabolic function and ammonia detoxification. Traumatic brain injury or stroke may create physical damage which in turn causes glutamate to bring hyper excitation and thereby killing neurons, thus resulting in brain damage [44].

Norepinephrine assists the body to go into "high alert" and is responsible for 
increasing heart rate and blood pressure. Norepinephrine can activate not only pre but post synaptic adrenergic receptors. Norepinephrine is released in the brain as the locus coeruleus is stimulated and action potential occurs. It is also important for the long-term memory by influencing surges in specific neural circuits. When norepinephrine binds to a receptor and stimulates a nerve to respond, it works as a neurotransmitter. When it is originated in the adrenal medulla as a product of dopamine, it works as a hormone (Epinephrine and Norepinephrine, https://www.boundless.com/blog/biology/).

Epinephrine is another flight/fight hormone released when the body is under extreme stress. It is closely related to norepinephrine since it is synthesized from norepinephrine in the adrenal medulla. Norepinephrine and epinephrine act on beta and alpha receptors, the difference is that norepinephrine is primarily focused on alpha receptors, whereas epinephrine stimulates all three beta receptors as well as alpha receptor.

Dopamine is the precursor molecule to both norepinephrine and epinephrine in the catecholamine synthesis pathway. This important neurotransmitter is produced several areas of the brain. The midbrain is host to the substantia nigra, which is a part of the basal ganglia and plays an important role in the reward system, voluntary motor movements, cognition and emotions. High levels of neuromelanin in dopaminergic neurons make substantia nigra appear darker than surrounding areas [45]. One function of dopamine is movement; the caudate and putamen create the striatum, which is a bundle of dopaminergic neurons that form the nigrostriatal pathway considered a facilitator of movement. The second function is that of the reward system, which originates in the ventral tegmental area of the brain. Wolfram Schultz's 1990 experiment demonstrated that dopamine release was associated more with unpredictability rather than with mere experience or a reward system. There are two main metabolites of dopamine: Norepinephrine and DOPAC, which is correlated with oxidative stress.

Serotonin (produced in the enteric nervous system of the gastrointestinal tract and in the central nervous system) has many important roles in overall health and wellbeing. It is a chemical product of nerve cells and serves in the modulation of glutamate excitation through voltage potential regulation. Serotonin is a metabolite of 5-HTP; up to $90 \%$ of serotonin is produced in the gastrointestinal tract, although it is also found in platelets and throughout the central nervous system. Serotonin is involved with smooth muscle contraction, regulating cyclic body processes and nerval impulse transmission. Most agree serotonin is the primary neurotransmitter for mood regulation [46]. Serotonin must originate in the brain if it is to be utilized by the brain. It is widespread in its roles and influences mood, digestion, ambition, social behavior, memory and sexual function. Serotonergic hypo function has been demonstrated to be a neurochemical trait associated with or precursor to impulsivity and aggression [46]. Serotonin also acts as a precursor to melatonin, which plays a major role in the body's circadian rhythm and sleep cycles. Both dopamine and serotonin have a close relationship 
in mood, anxiety, and aggression. The inhibitory and excitatory relationship between these two neurotransmitters has been the subject of numerous studies [46] [47] [48]. The main metabolite of serotonin is 5-HIAA. In our study, we analyzed 5-HIAA to obtain insight into the production of serotonin and the potential absorption concerns due to the tryptophan metabolites.

Taurine is a trophic factor and assists in the survival of synaptic neurons. Taurine is a neuromodulator and is protective against glutamate-induced excitotoxicity through limiting increase of intracellular calcium levels. This is achieved by shifting the ratio of BCL-2 and BAD ratio in favor of cell survival and reducing endoplasmic reticulum stress. Taurine plays an integral part in regulation of the amount of sensory information received by the cortex. Taurine is partly responsible for helping the brain to turn off at night by activating $G A B A$, it is stopping the thalamus (processing input from the senses) from waking up a sleeping person [49] [50]. Taurine is also involved in maintaining metabolic homeostasis in the body by reducing blood glucose levels and helps restore insulin sensitivity. Studies have demonstrated that taurine can reverse tinnitus, since many issues with hearing are a result of nerve cell communication with the brain as opposed to mechanical issues. Taurine assists in calcium restoration and control of auditory cells. Taurine is also involved in cortisol elimination, therefore mitigating stress responses within the body [49] [51] [52].

Histamine has many physiological roles within the body, one of which is the ability to increase excitability of the central nervous system. Studies have demonstrated that histamine can be a regulator of "whole brain" activity. Studies have also confirmed the potential of histamine to assist in mediation of alertness and electrographic arousal [53] [54] [55]. The hypothalamus's ventral preoptic center assists in turning off histaminergic tuberomammillary cells which connects to the sleep/wake cycle resulting in diurnal changes in brain function. Many functions of the hypothalamus are regulated by histamine. Vasopressin is physiologically regulated by histaminergic neurons [54] [55]. Additional studies demonstrate the potential of histamine for regulating levels of ACTH, prolactin, and oxytocin [55].

Glycine is another inflammation regulator; it plays an important role in overall health and wellness of the body. Glycine can be produced by the liver in limited amounts and is used for detoxification. Glycine helps with synthesis of bile acid, amino acids, and assists in the building of DNA, RNA and protein. By being involved in the manufacturing of immune-related hormones, it also plays a role in immunological function. Glycine is found in the spinal cord, brain stem, retina, and throughout the central nervous system. It acts on inflammatory cells such as macrophages to suppress activation of transcription factors and the formation of free radicals and inflammatory cytokines. Glycine is not just an anti-inflammatory agent, but also an immunomodulator and cytoprotective agent [56]. Excessive amounts of glycine can lead to decreased energy, anxiousness, sleep difficulties, as well as immune dysregulation and digestive stress.

PEA (phenylethylamine) is an excitatory neurotransmitter that assists in 
modulation of action potentials to enhance glutamate activity and neurotransmitter firing. It has been demonstrated that amongst the ADHD population there were consistently lower levels of $P E A$ and $P E A$ metabolites [57]. PEA has a tremendous impact on overall body alertness and physiological performance. Emotions are regulated in limbic region and having a very high concentration of $P E A$ makes an impact on motivation, emotions and socialization. Because it is an endogenous stimulant, $P E A$ enhances dopamine, norepinephrine and serotonin. $P E A$ causes fast impulse-mediated release of catecholamines (dopamine and epinephrine) and serotonin in the brain, resulting in rapid improvement of cognitive performance, attention, awareness, pleasure, libido, and overall sense of wellbeing [58]. Furthermore, increase in PEA improves alertness and higher cognitive functioning [48]. PEA can increase catecholamine levels and block re-uptake of dopamine, norepinephrine, and serotonin. This can bring restoration of energy as well as mood elevation. However, too much PEA can lead to anxiety. Studies demonstrate that those with ADHD will show either low or high levels of PEA. High levels can also be associated with anxiety, insomnia and mind racing [57] [59].

\section{Materials and Method}

\subsection{Demographic Data}

Two basic cohorts of individuals were involved in present research-the Study Group $(\mathrm{n}=80)$, and the Control Group $(\mathrm{n}=117)$. The Study Group was divided into four main demographics: Study Group 1-developmental disorders; Study Group 2-cerebral palsy, TBI, ABI, and seizures; Study Group 3-ADD and ADHD, and Study Group 4-anxiety disorders. The detailed description of the study groups is given below in the table.

Study Group composition $(\mathrm{n}=80)$. The study group was composed of individuals with different diagnosed disorders:

1) Study Group 1: Developmental disorders $(n=45)$ were diagnosed with one or more of the following developmental disorders: Autism spectrum disorder $(n=21)$, such as Asperger's, Pervasive Developmental Disorder-Not Otherwise Specified (PDD NOS), CHARGE syndrome $(n=5)$ (abbreviations of symptoms: Coloboma, Heart defect, Atresia choanae, Restricted growth and development, Genital abnormality, Ear abnormality), Down syndrome (8), and general developmental delay (11). Eight subjects were taking medication or supplementation at the time of sample submission. All participants were between the ages of 3 and 26 years (mean age $12 \pm 6$ years) measured a BMI of between 15 and 23 (mean BMI $18 \pm 3$ BMI). 15.6\% were female, 84.4\% male. All 45 subjects underwent the MNRI therapy program.

2) Study Group 2: Cerebral Palsy, TBI, ABI and seizures s $(n=14)$ were diagnosed with one or more of the following neurological disorders: Cerebral palsy $(n=5)$, TBI and ABI $(n=4)$, seizures and Tourette's $(n=5)$. Six subjects were taking medication or supplementation at the time of sample submission. The 
participants were between the ages of 4 and 48 years (mean age $12 \pm 13$ years) measuring a BMI between 13 and 21 (mean BMI $16 \pm 3$ BMI). 35.7\% of subjects were female and $64.3 \%$ male. All 14 subjects underwent the MNRI therapy program.

3) Study Group 3: ADD and ADHD $(n=11)$ were diagnosed with either Attention-deficit disorder $(\mathrm{n}=7)$ or Attention-deficit/hyperactivity disorder $(\mathrm{n}=$ 3). Three subjects were taking medication or supplementation at the time of sample submission. All participants were between the ages of 8 and 16 years (mean age $11 \pm 3$ years) measuring a BMI between 14 and 23 (mean BMI $18 \pm 3$ BMI). $27.3 \%$ of subjects were female and $72.7 \%$ male. All 14 subjects underwent the MNRI therapy program.

4) Study Group 4: Anxiety disorders $(n=10)$ were diagnosed with one or more of the following anxiety disorders: Anxiety $(\mathrm{n}=3)$, OCD (3), and PTSD ( $\mathrm{n}$ $=4)$. None of these subjects were taking medication or supplementation at the time of sample submission. Participants all were between the ages of 7 and 51 years (mean age $19 \pm 18$ years) with measured BMI between 17 and 35 (mean BMI $21 \pm 6$ BMI). $70 \%$ of the subjects were female and $30 \%$ male. All 10 subjects underwent the MNRI therapy program.

\section{Healthy Control Group Composition:}

Control subjects $(n=117)$ were recruited from general healthy population of both genders. At the time of sample submissions, the healthy control subjects did not have any inflammatory diseases or disorders, and have been confirmed to have no allergies, arthritis, asthma, cardiovascular disease, fibromyalgia, high blood pressure, thyroid disorder, type I and II diabetes, celiac disease, irritable bowel syndrome, Crohn's disease, Lyme disease, and bacterial, viral, or fungal infections. The control group did not have the following complaints and mental disorders: attention-deficit/hyperactivity disorder, anxiety, autism and Asperger's syndrome, Alzheimer's disease, chronic migraines, depression, insomnia, obsessive compulsive disorder, or Parkinson's disease. None of the individuals in the control group were taking medications or supplements at the time of sample submission. All subjects were between the ages of 6 and 25 years (mean age $18 \pm$ 5 years), with BMI between 12 and 30 (mean BMI $21 \pm 4$ BMI). $48 \%$ of the subjects were female, $52 \%$ were male.

\subsection{Analysis of Neurotransmitters}

The urine test panel for study included 12 neurotransmitters applied to Study (n $=80)$ and Control $(\mathrm{n}=117)$ groups. The urine collection was performed on the first day of the conference and again at the last day of the conference, urine collection was per manufacturer's specifications. The urinalysis test utilized was the \#9123 extended panel, testing twelve neurotransmitters, particularly: epinephrine, norepinephrine, dopamine, 3, 4-dihydroxyphenylacetic acid (DOPAC), serotonin, 5-HIAA, glycine, taurine, GABA, glutamate, PEA, and histamine.

Prior to the sample collection, the participants were ordered to fast for 8 hours 
and abstain from tobacco, avoid strenuous workouts, and not take supplements or medications (unless instructed otherwise by a physician). The urine collected was the second urine of the day collected 2 hours following wake up while still fasting. Two $5 \mathrm{ml}$ tubes were collected to accommodate the volume needs. One vial contained a stabilizer as specified to maintain the integrity of the sample. The samples were kept refrigerated until processed in the reference lab.

Urinary samples were processed blindly by a CLIA accredited reference laboratory, Pharmasan Labs (Osceola, WI) to quantitatively measure twelve urinary neurotransmitters: epinephrine (1), norepinephrine (2), dopamine (3), DOPAC (4), serotonin (5), 5-HIAA (6), glycine (7), taurine (8), GABA (9), glutamate (10), $P E A$ (11), and histamine (12). The reference laboratory-generated participant reports and provided external control data $(\mathrm{n}=117)$ with a comparative statistical analysis between control and study participants. In short, descriptive statistics of mean, standard deviation (SD), and Cohen's d (d) effect size were calculated in Excel (Office 2013 v15, Microsoft, Redmond, WA). The effect size for each parameter between groups was assessed by calculating Cohen's $d$. A $d$ value between $\pm[0.2-0.5]$ is a small effect, $\pm[0.5$ 0.8 ] a medium effect, and a value greater than +0.8 or less than -0.8 is a large effect. An ANOVA was performed using GraphPad Prism (v7, GraphPad Software, San Diego, CA) employing the Holm-Sidak's multiple comparison model to calculate the statistical significance ( $p$ value, $\alpha=0.05$ ) between control and sample for each group.

\subsection{The MNRI Reflex Integration Therapy Modality}

Each session was focused on a process of neurodevelopment called reflex integration session or module. The MNRI process included the following MNRI modules:

1) Reflex Repatterning-focuses on paving and improving the connectivity between the sensory and motor neurons in a reflex circuit [6] [7] that influence the sensory-motor milestones, motor programming, planning and control, and also cognitive skills [9] [20] [21].

2) Neuro-Structural Reflex and Immune System Integration-focuses on improving the functions of reflexes responsible for postural control, spine flexibility, abdomen, and neck and limbs musculature tone regulation, release of core tendon guard creating positive protection and the feeling of being secure, and immune system, creating the immunomodulatory effect aimed at improvement of functions of the T-1 immunity, cytokinesis, CD-4, CD- 8 and other immune cells functions, anti-inflammatory effect, regulation of immunoglobulins (IgE, IgG and other) [13] [14] [15].

3) Neuro-Tactile Integration-focuses on the regulation and normalization of tactile sensitivity (hyper- or hypo-), coordination and integration of receptors, skin dermatomes, and overall peripheral and central nervous system for support of reflex repatterning and integration [21].

4) Archetype Movements Integration-focuses on the enhancement of the 
primary biomechanics of motor patterns (extension, flexion, rotation, stretching-compression, and other) giving support for structural aspect of numerous reflex patterns, development of automatic and consciously learned motor abilities and skills; also postural and motor control, with secondary improvement of the speed of perception, focusing, and memory, in sensory-motor integration, and cognitive functions [60].

5) Breathing Reflex Integration-focuses on the regulation and normalization of breathing reflex patterns, and the residuum volume of the lungs for normal breathing and creating sufficient protection and survival [61].

6) Stress and Traumatic Stress Release-focuses on reflex patterns that can impact the HPA stress-axis for letting go past negative stress and trauma, for trauma normalization by activation of stress hormones and neurotransmitters regulation [9] [16].

7) Proprioceptive-Cognitive Integration-focuses on improving proprioceptive-vestibular (balance) system-related reflexes for support of postural and motor control, with secondary improvement in motor-cognitive functions.

8) Oral-Motor/Visual-Auditory Reflexes Integration-focuses on improving oral-motor, articulation and speech abilities, as well as visual and auditory functions [17].

The basic goal of the MNRI module is to utilize reflex patterns for improvements of daily functioning of individuals with challenges of their sensory-motor integration, stress and immune system resilience, physical wellness, behavioral and emotional regulation, and cognitive skills. Usual duration of a Family Conference is eight days. The study participants receive six 50-minute sessions of MNRI therapy programs daily.

\section{Results}

The baseline data on analysis of neurotransmitters markers for individuals with global developmental disorders (Group 1), cerebral palsy, TBI, and seizures (Group 2), ADD and ADHD (Group 3), and anxiety disorders (Group 4) are presented in Table 2. The effect size was assessed using Cohen's $d$ (see Methods) to determine the change in neurotransmitter levels between pre- and posttreatment intervention.

\subsection{Study Group 1}

Study Group 1 -developmental disorders $(\mathrm{n}=45)$ : 5 -HIAA had a 0.0 effect. DOPAC had -0.4. Dopamine had -0.2. Epinephrine had 0.2. GABA had -0.1. Glutamate had -0.1. Glycine had -0.3. Histamine had 0.0. Norepinephrine had -0.2 . PEA had -0.3 . Serotonin had -0.3 . Taurine had -0.3 . All results are in the category of small effects (see Table 1, Table 2 and Figure 1).

\subsection{Study Group 2}

Study Group 2-cerebral palsy, TBI, ABI and seizures $(\mathrm{n}=14)$ : 5-HIAA had 0.2 

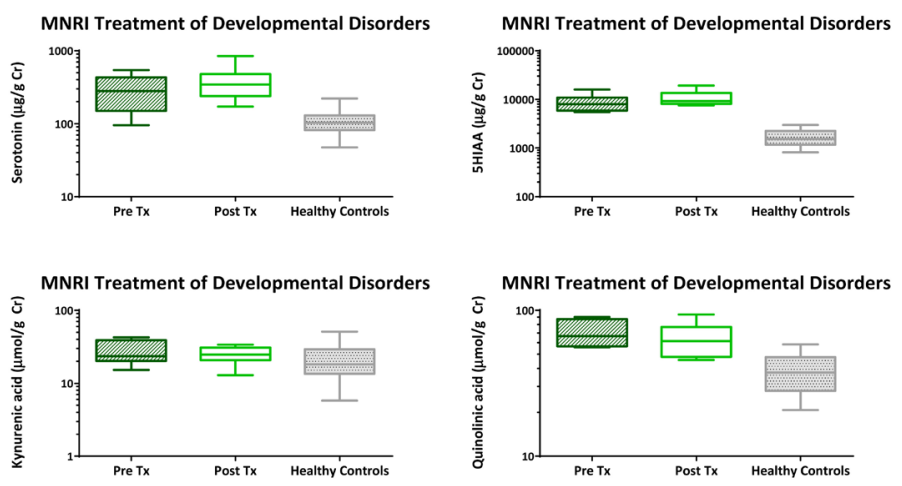

(a)
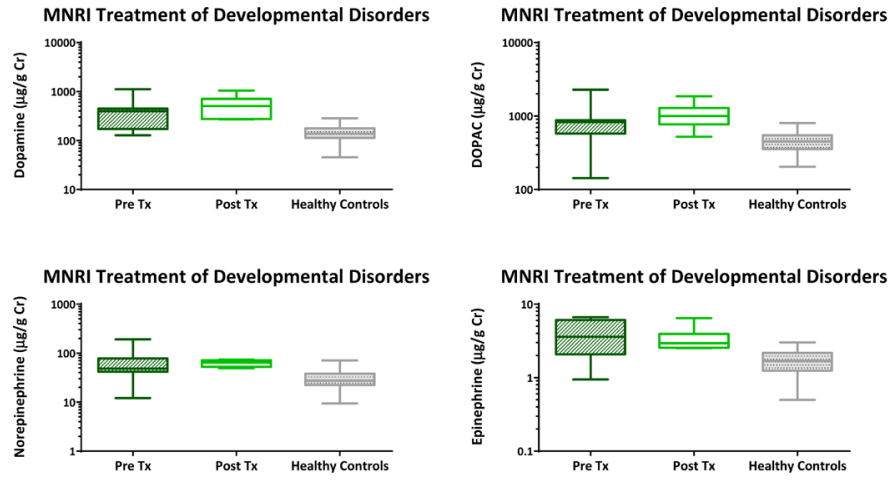

(b)
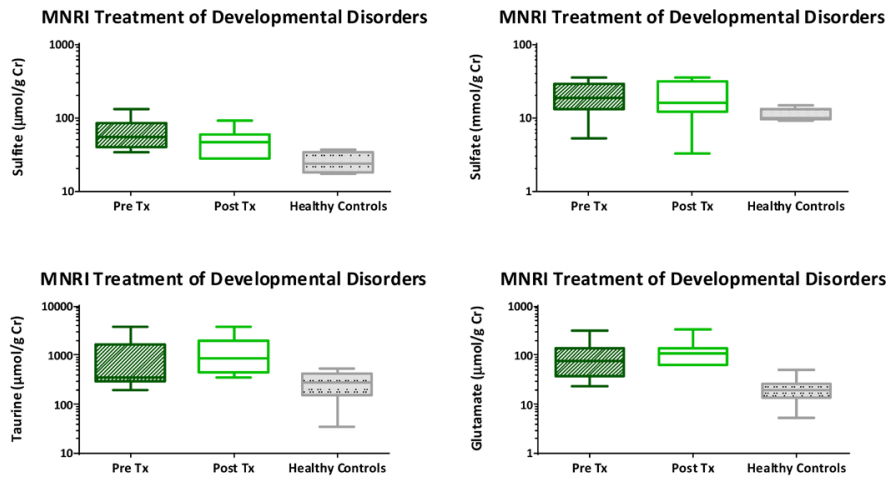

(c)
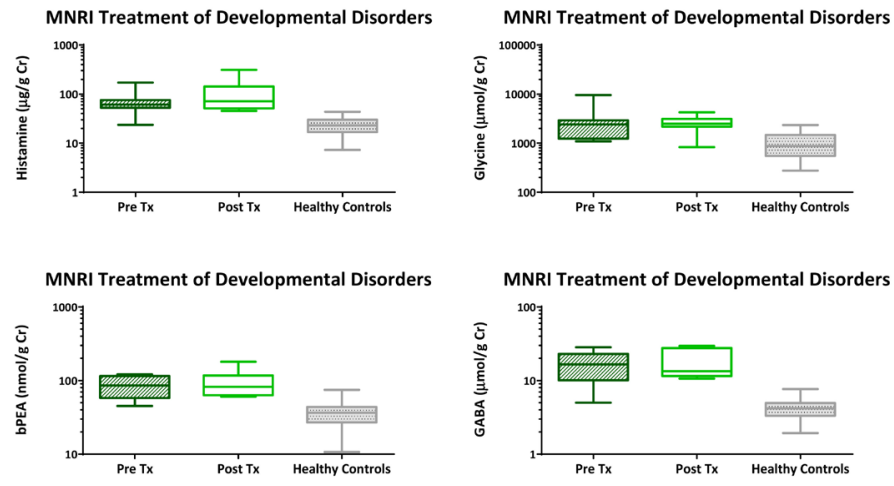

(d)

Figure 1. (a)-(d) Changes in neurotransmitters in Study Group 1-global developmental disorders $(n=45)$ after the MNRI program. 
Table 1. Demographic data of individuals in study groups (80) and control group (117).

\begin{tabular}{|c|c|c|c|c|c|}
\hline & & Study Groups $(\mathrm{n}=80)$ & & & \\
\hline Average Age & & $3-26$ & & & Group \\
\hline Average Mean Age & & $12 \pm 6$ & & & $(\mathrm{n}=11 /)$ \\
\hline & Group 1 & Group 2 & Group 3 & Group 4 & \\
\hline $\mathrm{N}$ & 45 & 14 & 11 & 10 & 117 \\
\hline & Developmental disorders: & Cerebral Palsy, TBI, ABI and seizures & $\mathrm{ADD}$ and $\mathrm{ADHD}$ & Anxiety Disorders & Neurotypical \\
\hline Diagnosis & $\begin{array}{c}\text { ASD }(\mathrm{n}=21), \\
\text { CHARGE }(\mathrm{n}=5) \\
\text { Down synd. }(8) \\
\text { General devel. delay }(11)\end{array}$ & $\begin{array}{c}\text { Cerebral Palsy }(n=5), \\
\text { TBI/ABI }(n=4), \\
\text { Seizures \& Tourette's }(n=5)\end{array}$ & $\begin{array}{c}\operatorname{ADD}(\mathrm{n}=7) \\
\operatorname{ADHD}(\mathrm{n}=3)\end{array}$ & $\begin{array}{l}\text { Anxiety }(\mathrm{n}=3) \\
\operatorname{OCD}(3) \\
\operatorname{PTSD}(\mathrm{n}=4)\end{array}$ & Healthy \\
\hline Age (y.o.) & $3-26$ & $4-48$ & $8-16$ & $7-51$ & $6-25$ \\
\hline Mean Age (y.o.) & $12 \pm 6$ & $12 \pm 13$ & $11 \pm 3$ & $19 \pm 18$ & $18 \pm 5$ \\
\hline BMI & 15 and 23 & $13-21$ & $14-23$ & $17-35$ & $12-30$ \\
\hline Mean BMI & $18 \pm 3$ & $16 \pm 3$ & $18 \pm 3$ & $21 \pm 6$ & $21 \pm 4$ \\
\hline Female & $15.6 \%$ & $35.7 \%$ & $27.3 \%$ & $70 \%$ & $48 \%$ \\
\hline Male & $84.4 \%$ & $64.3 \%$ & $72.7 \%$ & $30 \%$ & $52 \%$ \\
\hline
\end{tabular}

Table 2. The baseline data on neurotransmitters markers for individuals with global developmental disorders (Study Group 1), cerebral palsy, TBI, and seizures (Study Group 2), ADD and ADHD (Study Group 3), and anxiety disorders (Study Group 4).

\begin{tabular}{|c|c|c|c|c|c|c|c|c|c|c|c|c|c|c|c|c|c|c|c|}
\hline & & $\stackrel{\circ}{\alpha}$ & $\sum_{m}^{E}$ & 岕 & $\begin{array}{l}0 \\
\text { 岁 } \\
0 \\
0\end{array}$ & 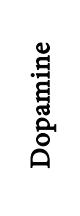 & 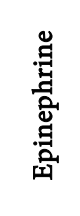 & 芯 & 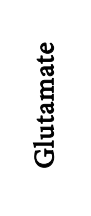 & 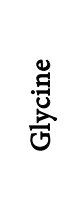 & 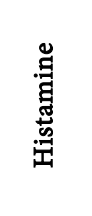 & 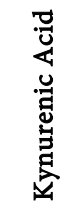 & 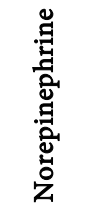 & 嵒 & 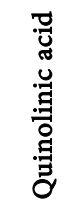 & 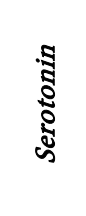 & 莺 & 壱 & 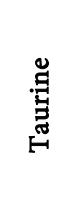 \\
\hline \multirow{6}{*}{$\begin{array}{l}\text { 氞 } \\
\text { 芶 } \\
\text { 焉 }\end{array}$} & $\mathbf{N}$ & & & 22 & 26 & 66 & 65 & 62 & 86 & 47 & 68 & 46 & 89 & 62 & 27 & 90 & 8 & 7 & 27 \\
\hline & 25 th $\%$ & 9 & 16 & 1217 & 372 & 113 & 1 & 3 & 14 & 590 & 17 & 14 & 23 & 28 & 29 & 81 & 9 & 20 & 169 \\
\hline & Median & 18 & 21 & 1545 & 451 & 138 & 2 & 4 & 20 & 876 & 23 & 18 & 27 & 37 & 37 & 103 & 10 & 23 & 274 \\
\hline & 75th \% & 25 & 28 & 2237 & 540 & 177 & 2 & 5 & 26 & 1414 & 30 & 28 & 37 & 44 & 48 & 129 & 12 & 29 & 410 \\
\hline & \multicolumn{2}{|c|}{ Mean } & & 1731 & 469 & 151 & 2 & 4 & 21 & 1005 & 24 & 21 & 31 & 38 & 38 & 109 & 11 & 25 & 291 \\
\hline & \multicolumn{2}{|c|}{ SD } & & 641 & 131 & 55 & 1 & 1 & 10 & 552 & 9 & 11 & 13 & 15 & 13 & 38 & 2 & 7 & 168 \\
\hline \multirow{8}{*}{ 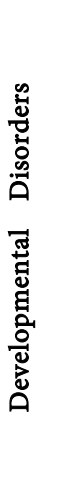 } & $\mathbf{N}$ & & & 45 & 45 & 44 & 44 & 45 & 45 & 45 & 45 & 19 & 45 & 45 & 19 & 45 & 18 & 19 & 45 \\
\hline & 25 th $\%$ & 3 & 14 & 4188 & 578 & 217 & 2 & 8 & 25 & 1154 & 29 & 16 & 35 & 46 & 41 & 150 & 8 & 19 & 198 \\
\hline & Median & 10 & 16 & 6154 & 798 & 374 & 3 & 10 & 51 & 1612 & 48 & 22 & 54 & 74 & 52 & 262 & 15 & 28 & 369 \\
\hline & 75th \% & 23 & 20 & 9297 & 1177 & 513 & 7 & 12 & 75 & 2215 & 69 & 35 & 79 & 101 & 59 & 339 & 27 & 46 & 644 \\
\hline & \multicolumn{2}{|c|}{ Mean } & & 8099 & 1110 & 367 & 7 & 11 & 63 & 1980 & 58 & 28 & 61 & 80 & 51 & 297 & 20 & 32 & 533 \\
\hline & \multicolumn{2}{|c|}{ SD } & & 6579 & 968 & 171 & 9 & 6 & 49 & 1275 & 45 & 19 & 36 & 46 & 17 & 232 & 17 & 18 & 546 \\
\hline & \multicolumn{2}{|c|}{$p$ Value } & & 0.000 & 0.001 & 0.000 & 0.000 & 0.000 & 0.000 & 0.000 & 0.000 & 0.083 & 0.000 & 0.000 & 0.006 & 0.000 & 0.137 & 0.332 & 0.028 \\
\hline & \multicolumn{2}{|c|}{ Cohen's } & & 1.2 & 0.8 & 1.9 & 0.9 & 1.7 & 1.4 & 1.0 & 1.2 & 0.5 & 1.3 & 1.3 & 0.9 & 1.4 & 0.7 & 0.4 & 0.5 \\
\hline
\end{tabular}


Continued

\begin{tabular}{|c|c|c|c|c|c|c|c|c|c|c|c|c|c|c|c|c|c|c|c|}
\hline \multirow{8}{*}{ 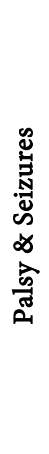 } & $\mathbf{N}$ & & & 14 & 13 & 13 & 12 & 14 & 14 & 14 & 14 & 9 & 14 & 14 & 9 & 14 & 9 & 9 & 14 \\
\hline & 25 th \% & 4 & 13 & 9200 & 667 & 394 & 2 & 13 & 77 & 1968 & 43 & 23 & 47 & 55 & 63 & 172 & 16 & 41 & 195 \\
\hline & Median & 7 & 15 & 11027 & 826 & 408 & 3 & 16 & 89 & 2775 & 60 & 28 & 69 & 66 & 74 & 241 & 21 & 61 & 850 \\
\hline & 75th \% & 39 & 20 & 18058 & 1726 & 522 & 5 & 20 & 118 & 5168 & 80 & 38 & 77 & 84 & 86 & 292 & 24 & 69 & 1531 \\
\hline & \multicolumn{3}{|c|}{ Mean } & 14508 & 1216 & 484 & 4 & 18 & 114 & 3714 & 71 & 29 & 81 & 86 & 74 & 259 & 20 & 61 & 1093 \\
\hline & \multicolumn{3}{|c|}{ SD } & 8444 & 858 & 242 & 2 & 8 & 73 & 2456 & 44 & 9 & 48 & 65 & 17 & 118 & 9 & 30 & 1130 \\
\hline & \multicolumn{3}{|c|}{$p$ Value } & 0.000 & 0.000 & 0.000 & 0.000 & 0.000 & 0.000 & 0.000 & 0.000 & 0.054 & 0.000 & 0.000 & 0.000 & 0.000 & 0.011 & 0.008 & 0.001 \\
\hline & \multicolumn{3}{|c|}{ Cohen's } & 2.4 & 1.5 & 3.1 & 2.0 & 3.6 & 3.3 & 2.2 & 2.4 & 0.7 & 2.4 & 1.6 & 2.6 & 2.7 & 1.4 & 1.6 & 1.2 \\
\hline \multirow{8}{*}{$\begin{array}{l}\text { 薏 } \\
\text { 是 } \\
\text { 合 } \\
\text { 究 }\end{array}$} & $\mathrm{N}$ & & & 11 & 11 & 11 & 11 & 11 & 11 & 11 & 11 & 7 & 11 & 11 & 7 & 11 & 6 & 6 & 11 \\
\hline & 25th \% & 7 & 14 & 4535 & 640 & 288 & 2 & 7 & 29 & 1620 & 37 & 19 & 42 & 48 & 44 & 152 & 7 & 24 & 261 \\
\hline & Median & 11 & 17 & 6366 & 774 & 343 & 3 & 8 & 51 & 2122 & 54 & 25 & 53 & 63 & 55 & 216 & 14 & 30 & 291 \\
\hline & 75th \% & 16 & 22 & 9434 & 1031 & 491 & 4 & 18 & 103 & 3144 & 72 & 32 & 80 & 77 & 58 & 319 & 21 & 38 & 449 \\
\hline & \multicolumn{3}{|c|}{ Mean } & 7298 & 1032 & 403 & 3 & 12 & 69 & 2696 & 59 & 25 & 68 & 70 & 50 & 247 & 14 & 30 & 367 \\
\hline & \multicolumn{3}{|c|}{ SD } & 3482 & 743 & 188 & 2 & 7 & 56 & 1826 & 39 & 9 & 47 & 28 & 12 & 106 & 8 & 10 & 252 \\
\hline & \multicolumn{3}{|c|}{$p$ Value } & 0.000 & 0.001 & 0.000 & 0.000 & 0.000 & 0.000 & 0.000 & 0.000 & 0.338 & 0.000 & 0.000 & 0.033 & 0.000 & 0.353 & 0.382 & 0.285 \\
\hline & \multicolumn{3}{|c|}{ Cohen's } & 2.7 & 1.4 & 2.9 & 1.7 & 2.6 & 2.3 & 1.8 & 2.2 & 0.4 & 1.9 & 1.8 & 0.9 & 2.8 & 0.5 & 0.5 & 0.4 \\
\hline \multirow{8}{*}{ 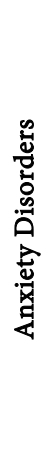 } & $\mathbf{N}$ & & & 10 & 10 & 10 & 10 & 10 & 10 & 10 & 10 & 3 & 10 & 10 & 3 & 10 & 3 & 3 & 10 \\
\hline & 25 th $\%$ & 7 & 17 & 3802 & 528 & 224 & 2 & 5 & 29 & 922 & 26 & 24 & 43 & 37 & 48 & 128 & 14 & 17 & 73 \\
\hline & Median & 8 & 19 & 4508 & 795 & 383 & 3 & 7 & 54 & 1497 & 30 & 30 & 45 & 45 & 54 & 205 & 14 & 25 & 153 \\
\hline & 75th \% & 48 & 31 & 6920 & 982 & 477 & 4 & 12 & 58 & 2153 & 33 & 36 & 64 & 84 & 61 & 243 & 16 & 25 & 375 \\
\hline & \multicolumn{3}{|c|}{ Mean } & 5286 & 951 & 374 & 5 & 11 & 49 & 1619 & 33 & 30 & 52 & 60 & 55 & 204 & 15 & 20 & 226 \\
\hline & \multicolumn{3}{|c|}{ SD } & 2219 & 744 & 161 & 6 & 10 & 22 & 890 & 15 & 12 & 22 & 34 & 13 & 90 & 2 & 9 & 182 \\
\hline & \multicolumn{3}{|c|}{$p$ Value } & 0.000 & 0.003 & 0.000 & 0.000 & 0.000 & 0.000 & 0.006 & 0.010 & 0.187 & 0.000 & 0.001 & 0.037 & 0.000 & 0.019 & 0.374 & 0.318 \\
\hline & \multicolumn{3}{|c|}{ Cohen's } & 2.7 & 1.2 & 2.9 & 1.7 & 1.7 & 2.4 & 1.0 & 0.9 & 0.8 & 1.5 & 1.2 & 1.3 & 2.1 & 1.9 & -0.6 & -0.4 \\
\hline
\end{tabular}

effect. DOPAC had 0.3. Dopamine had 0.4. Epinephrine had -0.1. GABA had 0.1. Glutamate had 0.2. Glycine had -0.3. Histamine had 0.5. Norepinephrine had -0.2. PEA had 0.3. Serotonin had 0.5. Taurine had 0.1. All results are in the category of small effects, except for histamine and serotonin which also fell into the lower tier of medium effect size (see Table 2, Table 3 and Figure 2).

\subsection{Study Group 3}

Study Group 3-ADD/ADHD ( $n=11)$ : 5-HIAA had -0.4 effect. DOPAC had 0.8. Dopamine had 0.1. Epinephrine had -0.7. GABA had -0.2. Glutamate had -0.5 . Glycine had -0.5. Histamine had -0.6. Norepinephrine had -0.2. PEA had -0.5 . Serotonin had 0.1. Taurine had -0.9 . The results in this specific category range from small to large effects (see Table 2, Table 4 and Figure 3).

Glutamate ( -0.5 medium effect). It is known that glutamate is an excitatory neurotransmitter that can be primarily associated with symptoms of aggression 

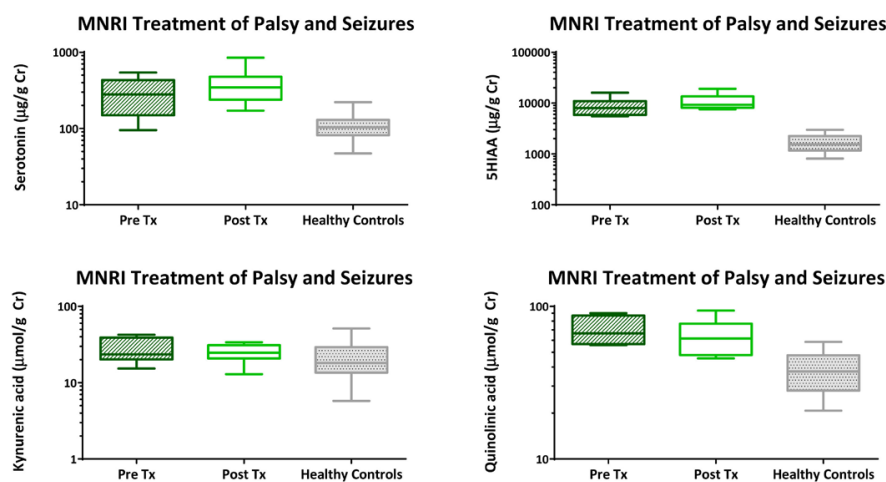

(a)
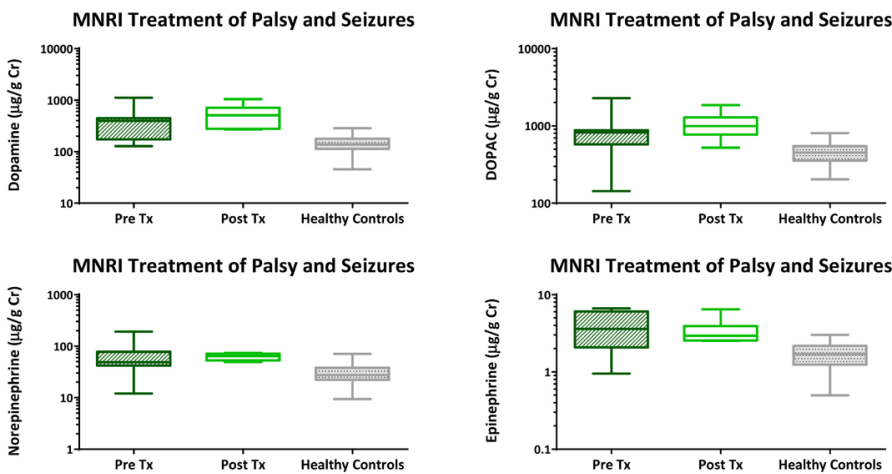

MNRI Treatment of Palsy and Seizures

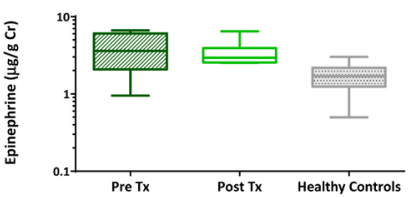

(b)
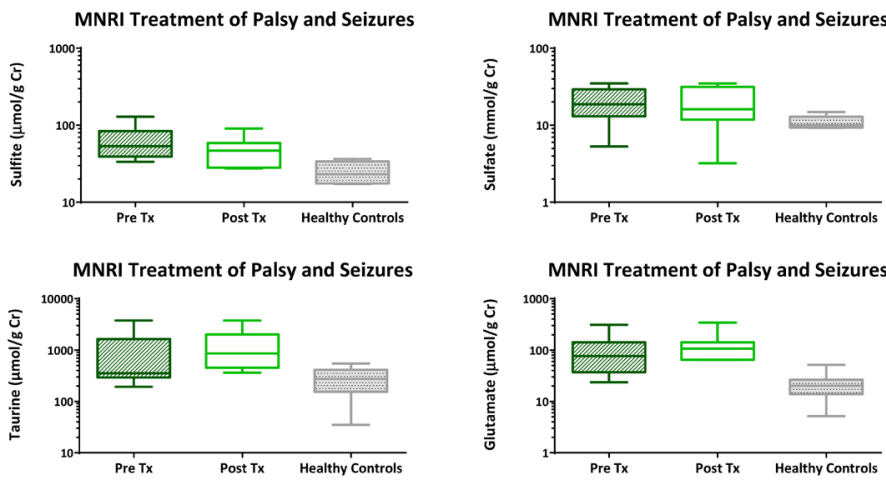

(c)
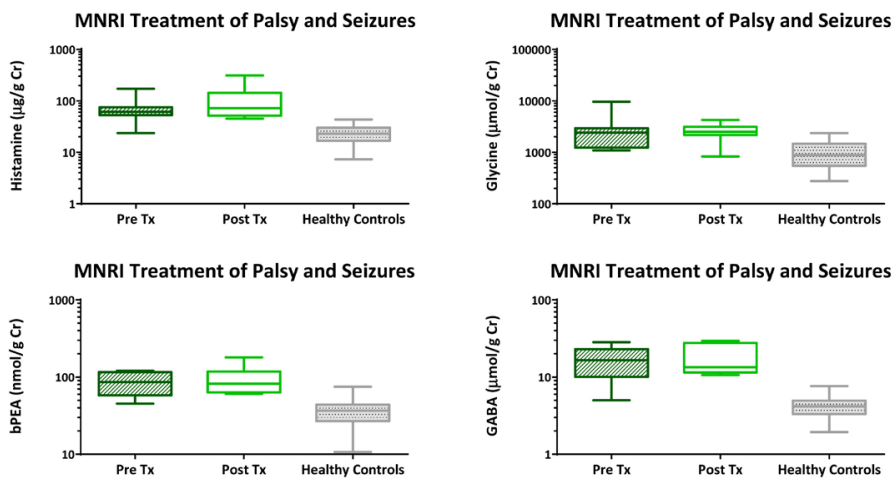

(d)

Figure 2. (a)-(d) Changes in neurotransmitters in Study Group 2-cerebral palsy, TBI, and seizures (Study Group 2; $n=14$ ) after the MNRI program. 

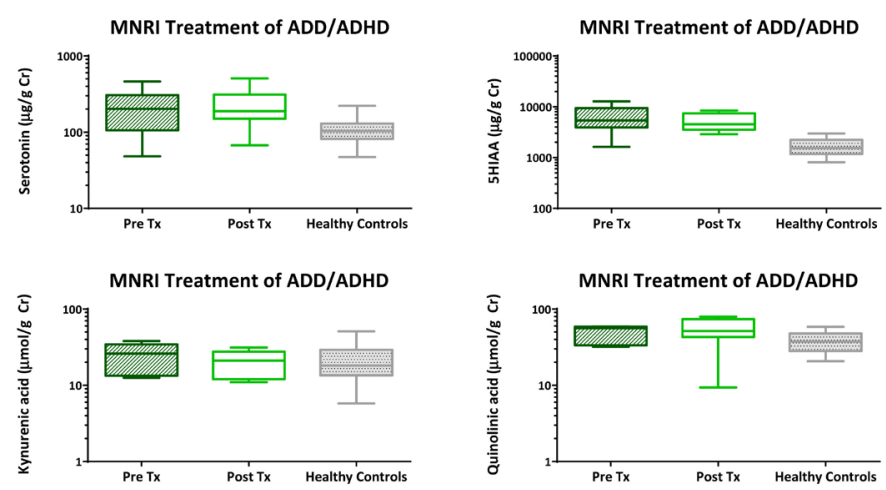

(a)
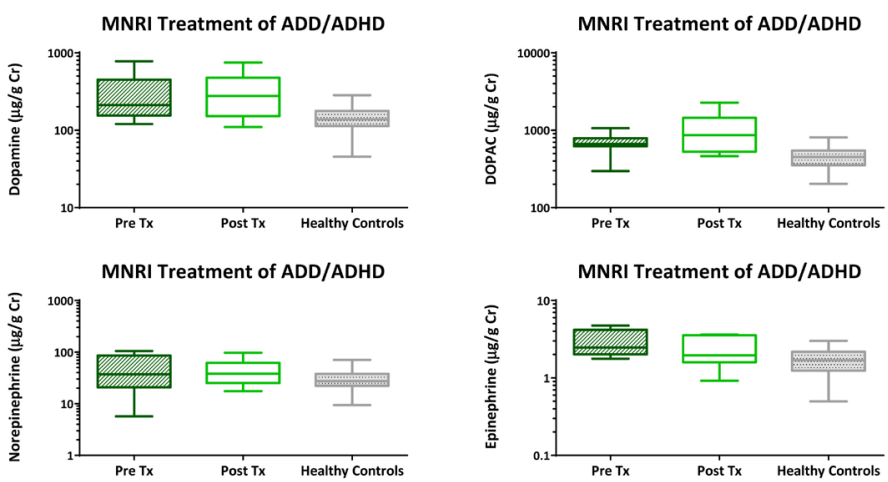

(b)
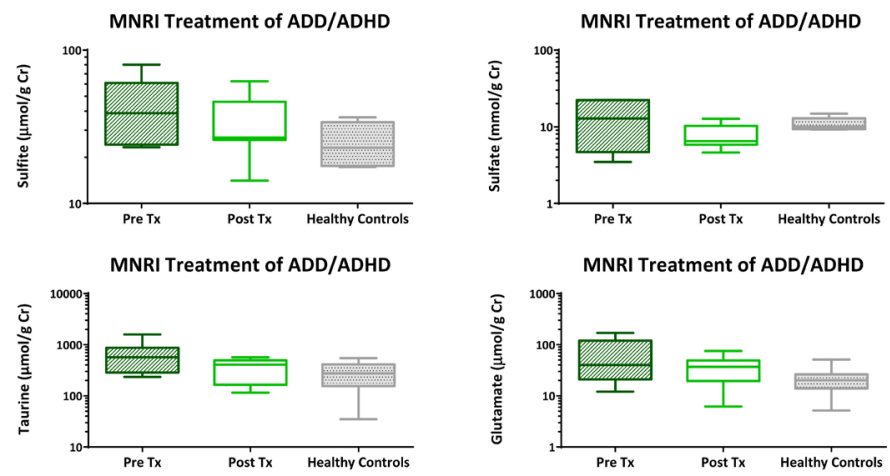

(c)
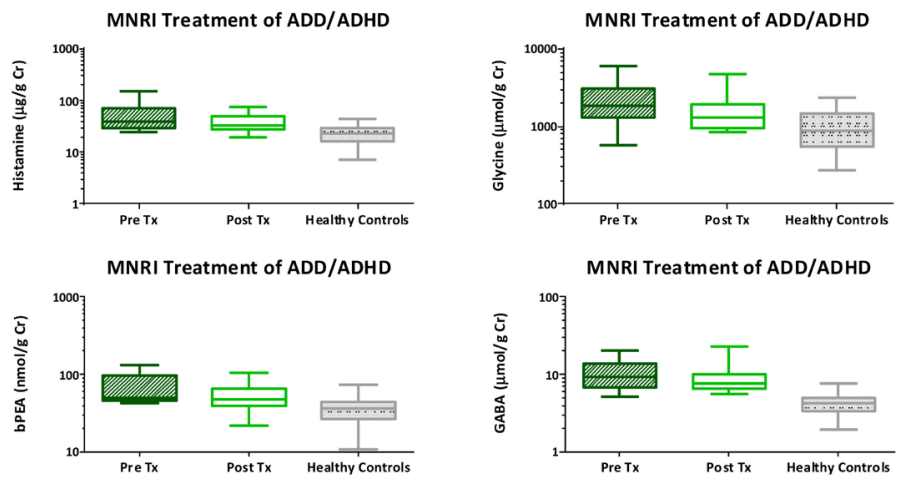

(d)

Figure 3. (a)-(d) Changes in neurotransmitters in Study Group 1-ADD and ADHD (Study Group $3 ; n=11$ ) after the MNRI program. 
Table 3. The baseline data on neurotransmitters markers for individuals with cerebral palsy, TBI, and seizures (Study Group 2; $n=14)$.

\begin{tabular}{|c|c|c|c|c|c|c|c|c|c|c|c|c|c|c|c|c|c|}
\hline & & 岕 & 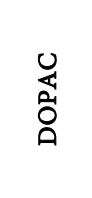 & 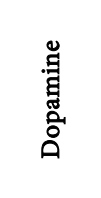 & 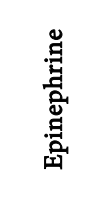 & 岕 & 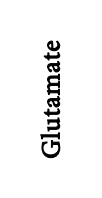 & $\frac{\stackrel{9}{0}}{\frac{2}{0}}$ & 莺 & 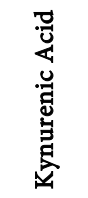 & 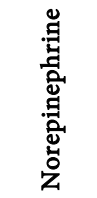 & 兵 & 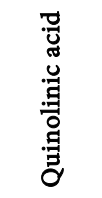 & 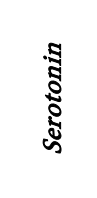 & 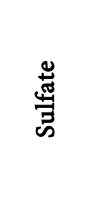 & 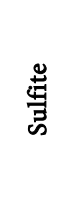 & 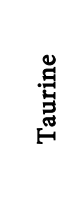 \\
\hline \multirow{3}{*}{$\begin{array}{l}\text { Pre } \\
\text { Tx }\end{array}$} & $\mathbf{N}$ & 7 & 7 & 7 & 6 & 7 & 7 & 7 & 7 & 6 & 7 & 6 & 6 & 7 & 6 & 6 & 7 \\
\hline & Mean & 11821 & 893 & 413 & 4 & 16 & 108 & 3143 & 74 & 27 & 70 & 86 & 70 & 291 & 20 & 63 & 1135 \\
\hline & SD & 8794 & 667 & 333 & 2 & 8 & 99 & 2922 & 46 & 10 & 58 & 29 & 15 & 156 & 10 & 34 & 1302 \\
\hline \multirow{3}{*}{$\begin{array}{l}\text { Post } \\
\text { Tx }\end{array}$} & $\mathbf{N}$ & 7 & 7 & 7 & 7 & 7 & 7 & 7 & 7 & 7 & 7 & 7 & 7 & 7 & 7 & 7 & 7 \\
\hline & Mean & 13636 & 1065 & 524 & 4 & 17 & 131 & 2563 & 111 & 25 & 63 & 95 & 63 & 387 & 20 & 50 & 1281 \\
\hline & $\mathrm{SD}$ & 8297 & 429 & 278 & 1 & 8 & 98 & 1032 & 94 & 7 & 9 & 43 & 17 & 228 & 12 & 21 & 1241 \\
\hline \multirow{3}{*}{ 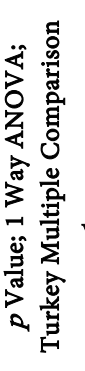 } & Healthy & & & & & & & & & & & & & & & & \\
\hline & $\begin{array}{c}\text { Controls } \\
\text { vs. Post Tx }\end{array}$ & $<0.0001$ & $<0.0005$ & $<0.0001$ & $<0.0001$ & $<0.0001$ & $<0.0001$ & $<0.0029$ & $<0.0001$ & 0.6507 & 0.0001 & $<0.0001$ & 0.0005 & $<0.0001$ & 0.1298 & 0.13 & 0.0075 \\
\hline & $\begin{array}{c}\text { Pre Tx } \\
\text { vs. } \\
\text { Post Tx }\end{array}$ & 0.2847 & 0.6103 & 0.2569 & 0.8521 & 0.9386 & 0.4518 & 0.595 & 0.0628 & 0.9144 & 0.8087 & 0.6677 & 0.5779 & 0.0522 & 0.9998 & 0.579 & 0.9261 \\
\hline \multicolumn{2}{|c|}{$\begin{array}{c}\text { Cohen's } \delta: \\
\text { Pre v Post Tx }\end{array}$} & 0.2 & 0.3 & 0.4 & -0.1 & 0.1 & 0.2 & -0.3 & 0.5 & -0.3 & -0.2 & 0.3 & -0.5 & 0.5 & 0.0 & -0.5 & 0.1 \\
\hline
\end{tabular}

Table 4. The baseline data on neurotransmitters markers for individuals with ADD and ADHD (Study Group 3; $n=11$ ).

\begin{tabular}{|c|c|c|c|c|c|c|c|c|c|c|c|c|c|c|c|c|c|}
\hline & & 㟔 & $\begin{array}{l}0 \\
\text { 岁 } \\
0 \\
0\end{array}$ & 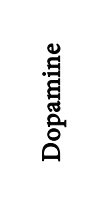 & 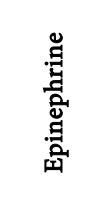 & 迎 & 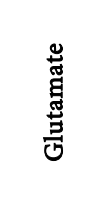 & $\underset{ }{\stackrel{0}{0}}$ & 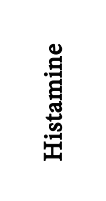 & 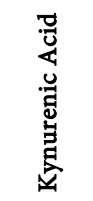 & 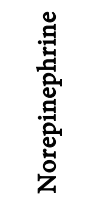 & 凬 & 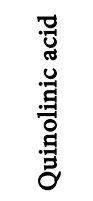 & 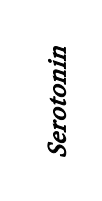 & 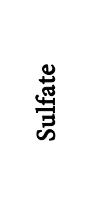 & 总 & 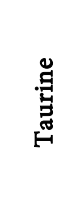 \\
\hline \multirow{3}{*}{$\begin{array}{l}\text { Pre } \\
\text { Tx }\end{array}$} & $\mathbf{N}$ & 9 & 9 & 9 & 9 & 9 & 9 & 9 & 9 & 6 & 9 & 9 & 6 & 9 & 5 & 5 & 9 \\
\hline & Mean & 6447 & 685 & 310 & 3 & 10 & 58 & 2426 & 57 & 25 & 52 & 68 & 49 & 210 & 13 & 42 & 648 \\
\hline & SD & 3695 & 202 & 220 & 1 & 5 & 58 & 1604 & 41 & 11 & 36 & 36 & 13 & 131 & 9 & 23 & 440 \\
\hline \multirow{3}{*}{$\begin{array}{l}\text { Post } \\
\text { Tx }\end{array}$} & $\mathrm{N}$ & 9 & 9 & 9 & 9 & 9 & 9 & 9 & 9 & 7 & 9 & 9 & 7 & 9 & 7 & 7 & 9 \\
\hline & Mean & 5250 & 1057 & 321 & 2 & 9 & 36 & 1688 & 38 & 21 & 46 & 54 & 51 & 229 & 8 & 35 & 357 \\
\hline & SD & 1996 & 607 & 212 & 1 & 5 & 21 & 1225 & 17 & 8 & 25 & 24 & 23 & 134 & 3 & 16 & 170 \\
\hline \multirow{3}{*}{ 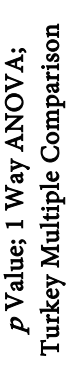 } & $\begin{array}{c}\text { Healthy } \\
\text { Controls } \\
\text { vs. Pre Tx }\end{array}$ & $<0.0001$ & 0.1635 & 0.0002 & $<0.0001$ & $<0.0001$ & $<0.0001$ & $<0.0001$ & $<0.0001$ & 0.7026 & 0.002 & $<0.0001$ & 0.2394 & $<0.0001$ & 0.6559 & 0.1958 & 0.0014 \\
\hline & $\begin{array}{c}\text { Healthy } \\
\text { Controls } \\
\text { vs. Post Tx }\end{array}$ & 0.0002 & $<0.0001$ & $<0.0001$ & 0.0851 & $<0.0001$ & 0.0734 & 0.0854 & 0.038 & 0.9997 & 0.0468 & 0.059 & 0.1181 & $<0.0001$ & 0.4088 & 0.5134 & 0.7622 \\
\hline & $\begin{array}{c}\text { Pre Tx } \\
\text { vs. } \\
\text { Post Tx }\end{array}$ & 0.4252 & 0.0316 & 0.9738 & 0.0806 & 0.6254 & 0.0078 & 0.1761 & 0.0365 & 0.7967 & 0.7 & 0.2432 & 0.9747 & 0.7804 & 0.1374 & 0.714 & 0.0407 \\
\hline \multicolumn{2}{|c|}{$\begin{array}{c}\text { Cohen's } \delta: \\
\text { Pre v Post Tx }\end{array}$} & -0.4 & 0.8 & 0.1 & -0.7 & -0.2 & -0.5 & -0.5 & -0.6 & -0.4 & -0.2 & -0.5 & 0.1 & 0.1 & -0.9 & -0.4 & -0.9 \\
\hline
\end{tabular}


in $A D D / A D H D$ patients [44] The pre-mean score was 58 with standard deviation was 58 . The post mean score was 36 with standard deviation of 21 (see Table 2, Table 4, and Figure 3). It received a p value of 0.0078 which is statistically significant and represents that there is less than $1 \%$ chance this finding was due to random chance.

Histamine ( -0.6 medium effect) acts as an excitatory neurotransmitter and also serves an important role in the body's immune response. Elevated levels are commonly associated with fatigue, sensitivities, and immune stress. Histamine had a pre-mean score of 57 with standard deviation of 41 . The post mean score was 38 with standard deviation of 17 . Histamine received a $\mathrm{p}$ value of 0.0365 , meaning that there is less than $4 \%$ probability that the difference in outcomes would be observed if the intervention had no benefit (see Table 2, Table 4, and Figure 3).

Taurine (-0.9 large effect). Taurine is a calming amino acid and can act as an agonist for both glycine and $G A B A$. Elevated levels can be associated with symptoms of excessive energy, anxiousness, sleep difficulties, and oxidative stress [51] [62]. Taurine had a pre-mean score of 648 with standard deviation of 440. The post-mean score was 357 with standard deviation 170 . The $\mathrm{p}$ value was statistically significant at 0.0407 .

\subsection{Study Group 4}

Study Group 4-anxiety disorders $(n=10): 5-H I A A$ had -0.1 effect. DOPAC had -0.2. Dopamine had 0.0. Epinephrine had 0.0. GABA had -0.2. Glutamate had -0.1. Glycine had 0.0. Histamine had -0.5. Norepinephrine had 0.0. PEA had -0.3. Serotonin had 0.1. Taurine had -0.9. This group also had a range of results from small to large effects (see Table 2, Table 5, and Figure 4).

Taurine had a -0.9 change which would indicate a large Cohen's effect [51] [52] [63]. Taurine pre-mean score was 604 with standard deviation of 535. The post treatment mean was 230 with standard deviation of 190 . The $\mathrm{p}$ value was 0.0153 which would translate into a $2 \%$ probability that our findings were due to chance (see Table 2, Table 5, and Figure 4).

\section{Discussion}

Our study demonstrated the impact on the neurological system from the MNRI treatment. The tested neurotransmitters are chemical messengers in our brain and body, delivering signals from one synapse to another. To ensure proper transmission from the presynaptic cell to the receptors of the postsynaptic cell the neurotransmitters must have appropriate genetic and chemical structure [29] [64]. Neurotransmitters participating in inhibitory or excitatory synapses determine functional properties of the underlying circuit. Depending on the specific pair of neurotransmitters and corresponding receptors, qualitative and quantitative features of the synapse vary due to the distinct kinetics and signaling cascades imprinted in the identity of the synaptic partners [64] [65]. This mechanism is determined by function of sensory neurons and, on other side, defines 

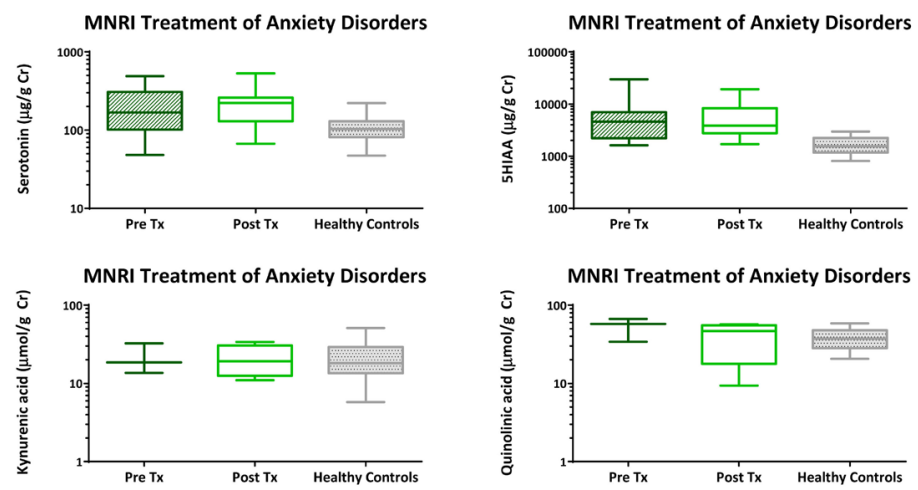

(a)
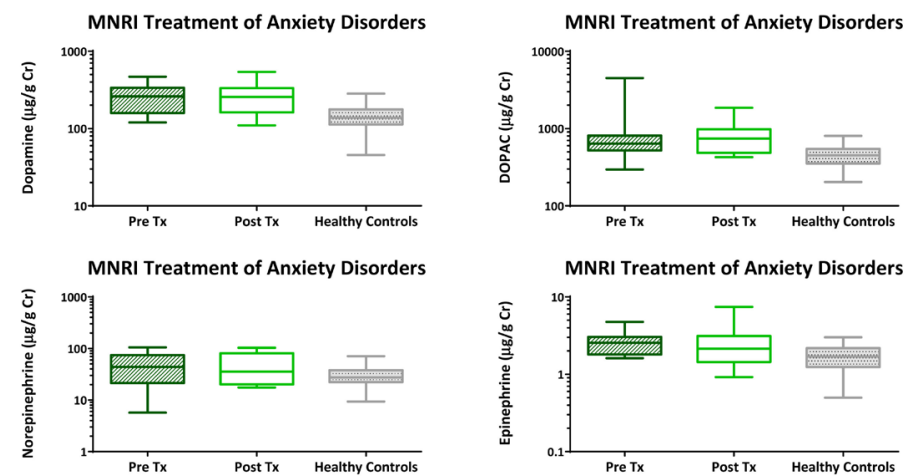

(b)
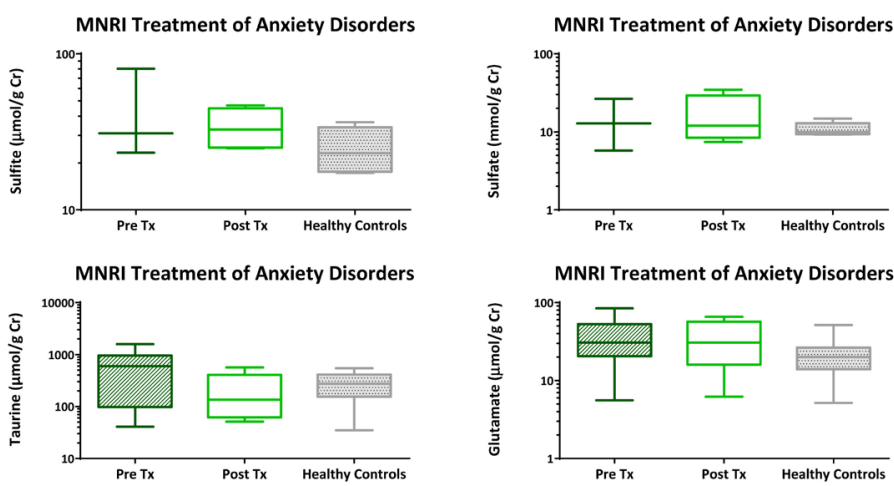

(c)
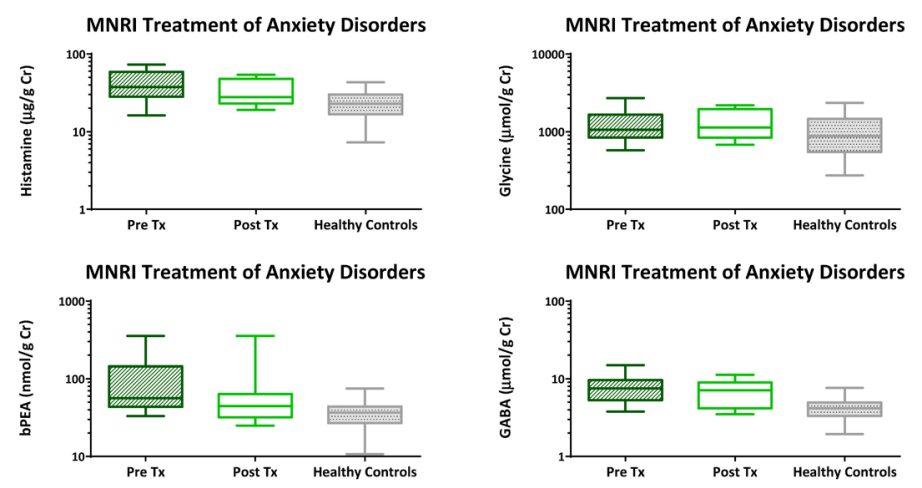

(d)

Figure 4. (a)-(d) Changes in neurotransmitters in Study Group 4-anxiety disorders (Study Group 4; $n=10$ ) after the MNRI program. 
Table 5. The baseline data on neurotransmitters markers for individuals with anxiety disorders (Study Group $4 ; n=10$ ).

\begin{tabular}{|c|c|c|c|c|c|c|c|c|c|c|c|c|c|c|c|c|c|}
\hline & & 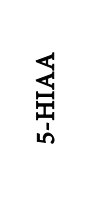 & $\begin{array}{l}\text { U } \\
\text { 望 } \\
0\end{array}$ & 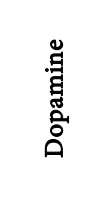 & 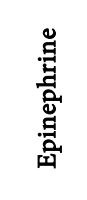 & ঙ্ৰ & 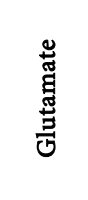 & 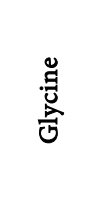 & 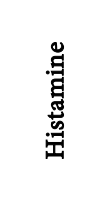 & 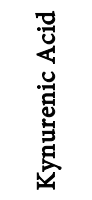 & 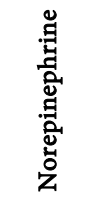 & 恖 & 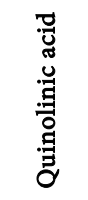 & 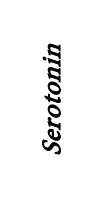 & 䒿 & $\frac{ \pm}{5}$ & 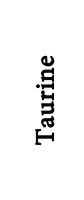 \\
\hline \multirow{3}{*}{$\begin{array}{l}\text { Pre } \\
\text { Tx }\end{array}$} & $\mathbf{N}$ & 10 & 10 & 10 & 10 & 10 & 10 & 10 & 10 & 3 & 10 & 10 & 3 & 10 & 3 & 3 & 10 \\
\hline & Mean & 7015 & 1003 & 263 & 3 & 8 & 37 & 1326 & 42 & 22 & 49 & 102 & 53 & 214 & 15 & 45 & 604 \\
\hline & SD & 8399 & 1240 & 113 & 1 & 3 & 24 & 638 & 18 & 10 & 31 & 102 & 17 & 151 & 11 & 31 & 535 \\
\hline \multirow[b]{2}{*}{$\begin{array}{c}\text { Post } \\
\mathrm{Tx}\end{array}$} & $\mathbf{N}$ & 10 & 10 & 10 & 10 & 10 & 10 & 10 & 10 & 4 & 10 & 10 & 4 & 10 & 4 & 4 & 10 \\
\hline & Mean & 6241 & 820 & 263 & 3 & 7 & 34 & 1340 & 34 & 21 & 50 & 75 & 40 & 221 & 17 & 34 & 230 \\
\hline \multirow{3}{*}{ 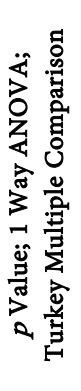 } & $\begin{array}{c}\text { Healthy } \\
\text { Controls } \\
\text { vs. Pre Tx }\end{array}$ & 0.0172 & 0.0576 & $<0.0001$ & 0.011 & $<0.0001$ & 0.0025 & 0.4144 & $<0.0001$ & 0.9988 & 0.0114 & 0.0008 & 0.2178 & $<0.0001$ & 0.7153 & 0.1923 & 0.0139 \\
\hline & $\begin{array}{c}\text { Healthy } \\
\text { Controls } \\
\text { vs. Post Tx }\end{array}$ & 0.0474 & 0.2771 & $<0.0001$ & 0.0074 & $<0.0001$ & 0.0121 & 0.2167 & 0.0217 & 0.9957 & 0.0066 & 0.0755 & 0.9769 & $<0.0001$ & 0.4804 & 0.6177 & 0.8364 \\
\hline & $\begin{array}{c}\text { Pre Tx } \\
\text { vs. } \\
\text { Post Tx }\end{array}$ & 0.9313 & 0.7788 & 0.9999 & 0.9939 & 0.6548 & 0.9206 & 0.9601 & 0.2296 & 0.9949 & 0.9898 & 0.4528 & 0.452 & 0.9682 & 0.9652 & 0.647 & 0.0153 \\
\hline \multicolumn{2}{|c|}{$\begin{array}{c}\text { Cohen's } \delta: \\
\text { Pre v Post Tx }\end{array}$} & -0.1 & -0.2 & 0.0 & 0.0 & -0.2 & -0.1 & 0.0 & -0.5 & -0.1 & 0.0 & -0.3 & -0.7 & 0.1 & 0.1 & -0.5 & -0.9 \\
\hline
\end{tabular}

characteristics of the processing of the input on level of neurotransmitter specification [29] [66] [67].

We have tested the following neurotransmitters: epinephrine (1), norepinephrine (2), dopamine (3), DOPAC (4), serotonin (5), 5-HIAA (6), glycine (7), taurine (8), GABA (9), glutamate (10), PEA (11), and histamine (12). Below the interpretation of neurotransmitter levels in pre- and post-intervention MRNI therapy for all study group $(\mathrm{n}=80)$ individually compared to the Healthy Control group $(n=117)$ is presented.

\subsection{Study Group 1}

Study Group 1 consisted of participants with developmental disorders $(\mathrm{n}=45)$. The results of the neurotransmitters analysis show improvement in levels of the DOPAC, dopamine, norepinephrine, $P E A$, serotonin, and taurine, all having a 0.2 - 0.3 impact, which would categorize as a small effect according to Cohen's method (see Table 1, Table 2 and Figure 1). This effect of reduction in excitatory neurotransmitter levels results in a decrease of inflammation in the neurological system, as well the reduction of neurodegenerative tendencies and positive tendency of restoration of nerve cell, which is similar to the findings of other authors [68] [69]. For instance, if serotonin as one of the modulators for glutamate causes significantly high level of glutamate, this could result in nerve dam- 
age or its death [70] [71]. There is also a known widespread negative effect when it concerns serotonin level increase influencing mood, digestion, ambition, social behavior, and memory [70] [72]. In the limbic region high concentrations and levels of $P E A$ can lead to anxiety, and lower levels may lead to depression, focus issues, and lack of ability to think clearly. This imbalance may have a profound impact on also social interactions [73].

We found a small effect size increase in Epinephrine (see Table 1, Table 2 and Figure 1). The overall down regulation of the excitatory neurotransmitters is consistent with the current literature [68] [69] regarding MNRI as a novel therapeutic technique for optimizing homeostasis in individuals with upregulated or hypersensitive neurological systems.

The post-MNRI results in participants in this group show tendency for regulation of neurotransmitters affecting the normalization of excitation and inhibition processes of the nerve system, for restoration of the nerve cells and homeostasis overall, also seen in clinical observations of improved motor activity, postural control, behavioral and emotional regulation, positive changes in cognitive processes-attention, memory and speed of thinking (see Table 1, Table 2 and Figure 1).

\subsection{Study Group 2}

Study Group 2 consisted of participants diagnosed with Cerebral Palsy, TBI, ABI and seizures $(\mathrm{n}=14)$. Small effect increases were measured in 5-HIAA, DOPAC, Dopamine, Glutamate, Norepinephrine, Histamine, PEA, and Serotonin levels. The impact of the MNRI intervention in this group was seen, particularly, in glycine and norepinephrine, at a $0.2-0.3$ effect, which would categorize as a small effect according to Cohen's method (see Table 1, Table 6 and Figure 2). Glycine plays a role with the inflammatory response and immune response of the organism [74]. This outcome can be estimated as significant as the impact of glycine due to its function to act as an immunomodulator and being cytoprotective [74]. The effect of the MNRI therapy is found in the improvement of the cytokinesis processes corresponding to immune studies done in MNRI in 2008-2016 [13] [19] [75]. Norepinephrine is a part of the sympathetic response, so a reduction as our study demonstrates can be considered as an impacting change in the body's physical response to stress, which is coherent to other researches in the area of this neurotransmitter [76]. Subsequently, changes in histamine considered to be a "powerful" regulator of "whole brain" activity and many hypothalamic functions [54] [77] [78] also can be interpreted as a factor for higher integrative brain functions, improvement in brain connectivity and neuroplasticity, novelty-induced attention and arousal.

Similar data also was found in some studies of this neurotransmitter as decisive for brain development and basis for major adaptation to changing environments by comparing news with the remembrance of things past, also for physiology of danger recognition, and survival [78]. 
Table 6. The baseline data on neurotransmitters markers for individuals with global developmental disorders (Study Group $1 ; n=$ 45).

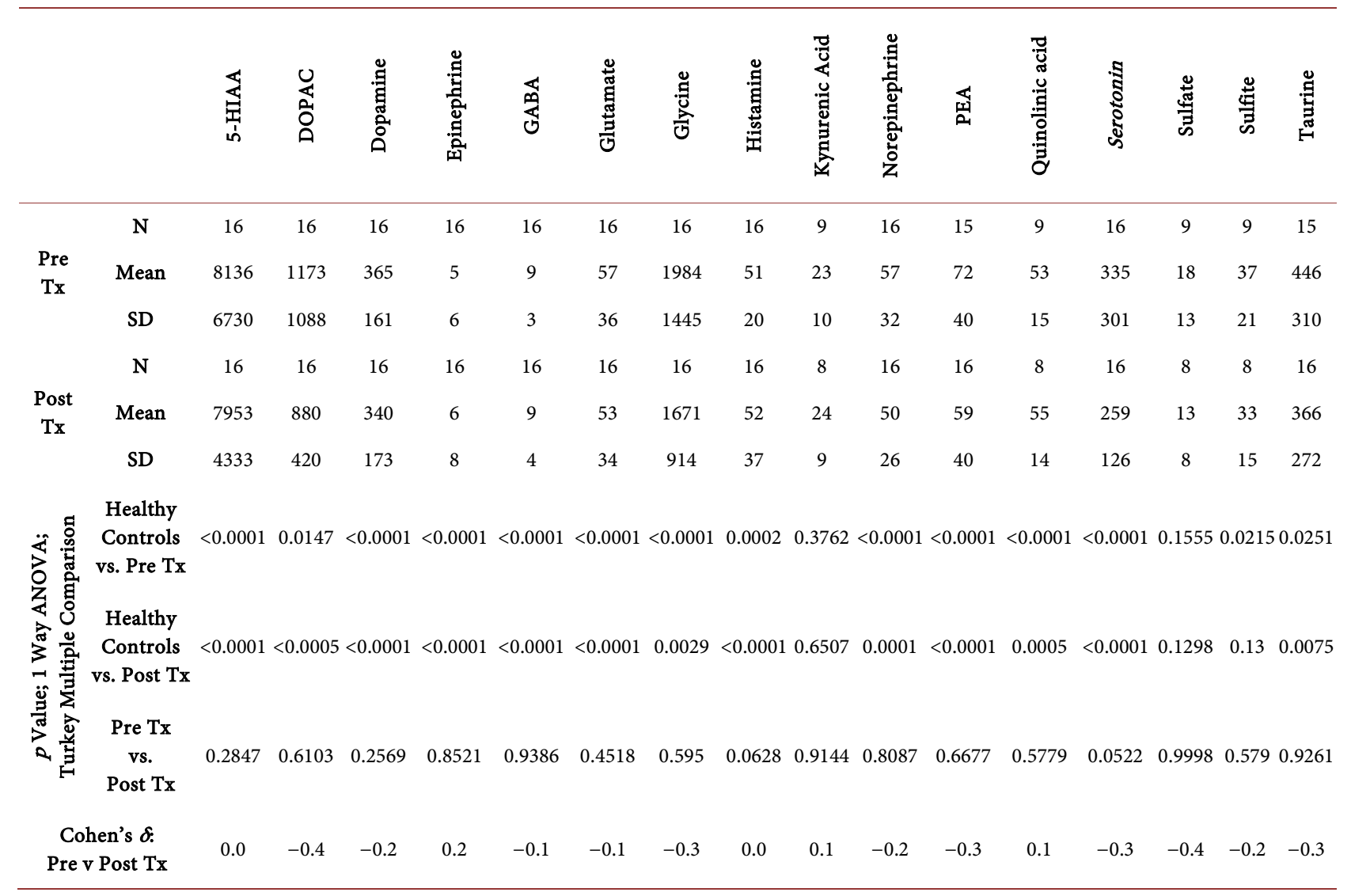

The data on regulating effect of the norepinephrine after the MNRI treatment was noted in reduction of negative chronic stress and clinically seen improvements in muscle tone regulation and in decrease of motor rigidity and pathology in reflex patterns (see Table 1, Table 6 and Figure 2). Clinical observation has also demonstrated regulatory effect of norepinephrine on mood, motivation for rehabilitation and more mobility and flexibility, better posture control and motor coordination. A significant reduction of seizure episodes during and after the MNRI intervention also took place, which corresponds to studies of the effects of this neurotransmitter on improvements on this health condition by other authors [79].

\subsection{Study Group 3}

Study Group 3 consisted of participants diagnosed with ADD/ADHD $(\mathrm{n}=11)$. The neurotransmitters post-tests after the MNRI intervention found large effect of decrease in taurine, medium effect decreases were found in epinephrine, glutamate, glycine, histamine and PEA. Small effect decreases were found in 5-HIAA, norepinephrine, and GABA. A medium effect increase was found in DOPAC levels (see Table 1, Table 3 and Figure 3). Interesting that our findings in this study group are more closely aligned to the overall down regulatory neu- 
rotransmitter levels of that in Study Group 1 (developmental disorders). The Cohen's effect sizes were much larger in Study Group 3 (see Table 1, Table 3 and Figure 3). As before mentioned, these neurotransmitters can have an impact of increasing immune response and inflammation in the body resulting in a reduction of improper excitability in the physiological system. This result is similar to those that are described in studies carried by other authors [72] [73] [74]. As before mentioned in Study Group 1, theoretically regulation for PEA could reduce symptoms of anxiety [73]. We can conclude that the MNRI treatment intervention had more profound neurophysiolocial changes in this subpopulation of patients. Clinical observations show that the participants of this Study Group 3 demonstrated remarkably improved ability to focus, enhanced memory, improved visual-auditory processing, and more readily self-regulate reactivity and emotional responses. Administration of standardized behavioral and symptom assessment tools at school and home would be useful to further detect the potential correlation between the treatment intervention, neurotransmitter level changes, and behavioral and ADD/ADHD symptom changes. MNRI therapy may be considered as an evident informed manual therapy intervention for those suffering from ADD/ADHD.

\subsection{Study Group 4}

Study Group 4 consisted of participants diagnosed with anxiety disorders $(\mathrm{n}=$ 10). The post-test of neurotransmitters after the MNRI intervention found large effect decreases in taurine and medium effect decreases were found in histamine levels. Small effect decreases were found in DOPAC, GABA, and PEA (see Table 1, Table 4 and Figure 4). This study group had several pre-treatment neurotransmitter levels which were closer to those levels of the Healthy Control Group, thus, we would not expect to detect as many significant effect changes in these neurotransmitters in participants of this study group. The decrease in taurine and histamine as it is known, is especially beneficial to those patients suffering from anxiety disorders [80]. Histamine is believed to be a major neuroexcitation regulator and a significant decrease in levels of it would theoretically reduce excitability of the central nervous system [71] [79]. The impact of taurine in the cortex is significant as it plays a role in how much sensory information the brain receives [80] [81]. Thus, decreases in these particular neurotransmitters will give neurological homeostasis and thereby reduction in anxiety and improved quality of life in individuals with anxiety who undergo the MNRI treatment. The long-term work with post-trauma individuals shows highly significant results [16] [24] [81].

Small effect decreases were found in PEA, DOPAC and GABA.

High levels of PEA, as known, are associated with anxiety, insomnia and mind racing [57] [59]. Thus, small effect decreases in PEA after the MNRI therapies can explain the observed easier regulation of emotions and improvement in behavioral control, also increased the ability to calm down and stress resiliency. 
$G A B A$ ergic and dopaminergic pathways are balancing excitatory-inhibitory process and neural network reconfigurations [40] [41] [82]. This explains the "calming down effect" and reduction of anxiety in participants of this Study Group. The effect of the DOPAC as a metabolite of dopamine, was in balance with the PEA metabolites [57] [83] was evidently allowing for rapid improvement of motivation, cognitive performance, ability to enjoy and play, and overall sense of wellbeing that we were observing in these participants. The normalization effect of these neurotransmitter levels lead to the restoration of energy, and mood elevation also is similarly described by other authors [84].

Overall, the post-MNRI results in participants in this group show tendency for regulation of the above neurotransmitters (see Tables 1-4, Table 6 and Figures 1-4) resulting in their calming down, decrease of hypervigilance, stress resilience increase, improvements in behavioral and emotional regulation, positive emotions, and cognitive processes control—attention, thinking, creativity, goal setting and easier decision making.

\section{Conclusion}

The present findings suggest that the MNRI treatment positively impacts central nervous, immune, and endocrine systems by regulation of the stress hormones and neurotransmitters regulation. The results indicate that through treatment using reflex patterns there is a reduction in the excitability within the nervous system, and reduction in the inflammatory response. All four study groups demonstrated positive changes that were generally small scale. The anxiety disorders group showed medium effect in the histamine response, and a large effect on the neurotransmitter taurine. The ADD/ADHD group had remarkable medium-to-large effects in most neurotransmitters. Neurotransmitter regulation can influence mood, behavior, focus, and cognitive functions. By regulation of the neurotransmitters and increasing the neuromodulation effect, the pathway for neurodevelopment, increase of stress resilience, neuroplasticity and new learning is facilitated. It is pertinent to note that modulation is achieved without the use of pharmaceuticals and their attendant risk of side effects.

\section{Acknowledgements}

The study was conducted during the MNRI Family Conferences across the United States.

\section{Ethical Approval}

This study was approved by New England IRB (\#: 20160464, Legacy IRB \#: 15-466, Action Date: 02/11/2016; A WIRB Copernicus Group Company). All specialists leading the evaluations were certified by the NIH (National Institute of Health, Office of Extra Mutual Research) "Protecting Human Research Participants" in 2012-2017. All participants were assigned codes to protect anonymity. Receipt of informed consent was received from all participants' parent or le- 
gal guardian. MNRI Therapy Program was conducted and treatment administered by designated Specialists or MNRI Core Specialists who have successfully completed the requirements for Continuing Professional Education in MNRI and clinical hours (www.MasgutovaMethod.com). Double blind analysis of research results and preparation of this report is done by independent experts.

\section{Conflicts of Interest}

The authors declare no conflicts of interest regarding the publication of this paper. The scientists performing the qualitative and quantitate analysis of these research results were not privy to details regarding the treatment or suspected outcomes. They also had no vested interest in MNRI.

\section{References}

[1] Pitman, R.K., Shin, L.M. and Rauch, S.L. (2001) Investigating the Pathogenesis of Posttraumatic Stress Disorder with Neuroimaging. The Journal of Clinical Psychiatry, 62, 47-54.

[2] Kollen, B., Lennon, S., Lyons, B., et al. (2009) The Effectiveness of the Bobath Concept in Stroke Rehabilitation. Stroke, 40, e89-e97.

https://doi.org/10.1161/STROKEAHA.108.533828 https://stroke.ahajournals.org/content/40/4/e89.full.pdf+html

[3] Delacato, C.H. (1974) The Diagnosis and Treatment of Speech and Reading Problems. Doubleday, Garden City.

[4] Vojta, V. (1989) Die Posturale Ontogenese als Basis der Entwicklungsstorungen. Monatsschr. Kinderheilkd.

[5] Pilecki, W., Kipiński, L., Szawrowicz-Pełka, T., Kałka, D. and Masgutova, S. (2013) Spectral Brain Mapping in Children with Cerebral Palsy Treated by the Masgutova Neurosensorimotor Reflex Integration Method. Journal of the Neurological Sciences, 333, e550. https://doi.org/10.1016/j.jns.2013.07.1932

[6] Pilecki, W., Masgutova, S., Kowalewska, J., Masgutov, D., Akhmatova, N., et al. (2012) The Impact of Rehabilitation Carried out Using the Masgutova Neurosensorimotor Reflex Integration Method in Children with Cerebral Palsy on the Results of Brain Stem Auditory Potential Examinations. Advances in Clinical and Experimental Medicine, 21, 363-371.

[7] Koberda, J.L. and Akhmatova, N. (2016) Masgutova Neurosensorimotor Reflex Integration (MNRI) as a New Form of Manual Neuromodulation Technique. Journal of Neurology and Neurophysiology, 2.

https://doi.org/10.16966/2379-7150.e110

[8] Koberda, J.L., Akhmatova, N., Akhmatova, E., Bienkiewicz, A., Nowak, K. and Nawrocka, H. (2016) Masgutova Neurosensorimotor Reflex Integration (MNRI) Neuromodulation Technique Induces Positive Brain Maps (QEEG) Changes. Journal of Neurology and Neurophysiology, 2. https://doi.org/10.16966/2379-7150.130

[9] Masgutova, S., Akhmatova, N., Sadowska, L., Shackleford, P. and Akhmatov, E. (2016) Progress with Neurosensorimotor Reflex Integration for Children with Autism Spectrum Disorder. Journal of Neurology and Psychology, 4, 14. https://doi.org/10.13188/2332-3469.1000028

[10] Masgutova, S., Akhmatova, N. and Akhmatov, E. (2016) Neurosensorimotor Reflex Integration for Autism: A New Therapy Modality Paradigm. Journal of Pediatric 
Neurological Disorders, 2, 107.

[11] Masgutova, S., Sadowska, L., Kowalewsk, J., Masgutov, J., Akhmatova, N. and Filipowski, H. (2015) Use of a Neurosensorimotor Reflex Integration Program to Improve Reflex Patterns of Children with Down Syndrome. Journal of Neurology and Neurosciences, 6, 59. https://doi.org/10.21767/2171-6625.100059

[12] Masgutova, S., Akhmatova, N. and Sadowska, L. (2016) Reflex Profile of Children with Down Syndrome Improvement of Neurosensorimotor Development Using the MNRI Reflex Integration Program. International Journal of Neurorehabilitation, 3, 197. https://doi.org/10.4172/2376-0281.1000197

[13] Akhmatova, N. and Akhmatova, E. (2016) Influence of MNRI on the Immune Status of Children with Down Syndrome. Journal of Clinical and Cellular Immunology, 8, 483. https://doi.org/10.4172/2155-9899.1000483

[14] Akhmatova, N., Akhmatova, E. and Lebedinskaya, O. (2016) MNRI: An Immunomodulating Effect on Lymphocyte Subpopulation Structure of Children with Down Syndrome. Russian Journal of Immunology, 10, 485-487.

[15] Akhmatova, E., Akhmatova, N. and Masgutova, S. (2016) MNRI: Immunocorrective Effect on the Immune Status of Children with Down Syndrome. 17th Biennial Meeting of the European Society for Immunodeficiencies, Barcelona, 21-24 September 2016.

[16] Masgutova, S. (2016) Post-Trauma Recovery in Children of Newtown, CT Using MNRI Reflex Integration. Journal of Traumatic Stress Disorders \& Treatment, 5, 5. https://doi.org/10.4172/2324-8947.1000163

[17] Masgutova, S. and Regner, A. (2008, 2011) Language Development Using Sensory-Motor Integration Approach. MISM, Wroclaw, $167 \mathrm{p}$.

[18] Akhmatova, N., Masgutova, S., Sorokina, E., Akhmatov, E. and Lebedinskaya, O. (2015) Influence of Neuro-Sensory-Motor Reflex Integration Technique on Immune Response of Patients with Herpes-Associated Multiforme Erythema. 11th Congress of the Latin American Association of Immunology, October 2015, Medellin.

[19] Masgutova, S., Akhmatova, S. and Kiselevsky, M. (2008) Immunologic Effects of Masgutova Neurosensorimotor Reflex Integration in Children with Recurrent Obstructive Bronchitis. Russian Journal of Immunology, 2, 454-463.

[20] Renard-Fontaine, I.F. (2017) Effect of Reflex Neuromodulation on an Infant with Severe Amniotic Band Syndrome: A Case Report on the Use of Mnri Techniques for Physical Therapy. International Journal of Neurorehabilitation, 4, 248. https://doi.org/10.4172/2376-0281.1000248

[21] Nowak, K. and Sendrowski, K. (2016) Neurophysiological Aspects of Neurotactile Therapy of Masgutova Neurosensory Motor Reflex Integration MNRI Method. Rehabilitacja Medyczna, 21, 20-29.

[22] Rentschler, M. and Averkamp, S. (2015) Reflexes: Portal to Neurodevelopment and Learning. A Collective Work. Svetlana Masgutova Educational Institute, Orlando.

[23] Selye, H. (1974) Stress without Distress. J. B. Lippincott Co., Philadelphia.

[24] Masgutova, S. (2016) PTSD Recovery: Gentle, Rapid, and Effective Treatment with Reflex Integration. SMEI, Orlando, $158 \mathrm{p}$.

[25] Sechenov, I.M. (1965) Reflexes of the Brain (Russ. Tr. Belsky, S.). The MIT Press, Cambridge.

[26] Sechenov, I.M. (1995) Physiology of Behavior. Scientific Works. Ed. M.G. Yaroshevsky, Moscow. 
[27] Pavlov, I.P. (1925/1960) Conditioned Reflexes: An Investigation of the Physiological Activity of the Cerebral Cortex. Anrep, G.V., Trans., 1960. Dover Publications Inc., New York.

[28] Anokhin, P.K. (1974) Biology and Neurophysiology of the Conditioned Reflex and Its Role in Adaptive Behavior. Pergamon Press, Oxford. https://doi.org/10.1016/B978-0-08-021516-7.50009-4

[29] Haines, D.E. (2002) Fundamental Neuroscience. 2nd Edition, The Curtis Center Independence Square West, Philadelphia.

[30] Virella, G., Goust, J.M. and Fudenberg, H.H. (1990) Introduction to Medical Immunology. 2nd Edition, Marcel Dekker, New York.

[31] Kagedal, B. and Goldstein, D.S. (1988) Catecholamines and Their Metabolites. Journal of Chromatography, 429, 177-233. https://doi.org/10.1016/S0378-4347(00)83871-2

[32] Westermann, B. (2002) Merging Mitochondria Matters: Cellular Role and Molecular Machinery of Mitochondrial Fusion. EMBO Reports, 3, 527-531.

https://doi.org/10.1093/embo-reports/kvf113

[33] Panholzer, T.J., Beyer, J. and Lichtwald, K. (1999) Coupled-Column Liquid Chromatographic Analysis of Catecholamines, Serotonin, and Metabolites in Human Urine. Clinical Chemistry, 45, 262-268.

[34] Bloom, F.E. and Kupfer, D.J. (1995) Psychopharmacology: The Fourth Generation of Progress. Raven Press, New York.

[35] Lynn-Bullock, C.P., Welshhans, K., Pallas, S.L. and Katz, P.S. (2004) The Effect of Oral 5-HTP Administration on 5-HTP and 5-HT Immunoreactivity in Monoaminergic Brain Regions of Rats. Journal of Chemical Neuroanatomy, 27, 129-138. https://doi.org/10.1016/j.jchemneu.2004.02.003

[36] Marc, D.T., Ailts, J.W., Campeau, D.C., Bull, M.J. and Olson, K.L. (2010) Neurotransmitters Excreted in the Urine as Biomarkers of Nervous System Activity: Validity and Clinical Applicability. Neuroscience \& Biobehavioral Reviews, 35 , 635-644. https://doi.org/10.1016/j.neubiorev.2010.07.007

[37] Borodinsky, L.N., Belgacem, Y.H., Swapna, I. and Sequerra, E.B. (2005/2012) Dynamic Regulation of Neurotransmitter Specification: Relevance to Nervous System Homeostasis. Neuropharmacology, 78, 75-80. https://doi.org/10.1016/j.neuropharm.2012.12.005

[38] MarcJoseph, D.T., Ailts, J.W., Ailts Campeau, D.C., Bull, M.J. and Olson, K.L. (2011) Neurotransmitters Excreted in the Urine as Biomarkers of Nervous System Activity: Validity and Clinical Applicability. Neuroscience \& Biobehavioral Reviews, 35, 635-644. https://doi.org/10.1016/j.neubiorev.2010.07.007

[39] Ziemssen, T. and Kern, S. (2007) Psychoneuroimmunology Cross-Talk between the Immune and Nervous Systems. Journal of Neurology, 254, II8-II11. https://doi.org/10.1007/s00415-007-2003-8

[40] Spitzer, N.C. (2010) How GABA Generates Depolarization. The Journal of Physiology, 588, 757-758. https://doi.org/10.1113/jphysiol.2009.183574

[41] Kriegsfeld, L.J. and Silver, R. (2006) The Regulation of Neuroendocrine Function: Timing Is Everything. Hormones and Behavior, 49, 557-574. https://doi.org/10.1016/j.yhbeh.2005.12.011

[42] Levinson, A.J. and Zafiris, J. (2010). https://www.eurekalert.org/pub_releases/2010-03/cfaa-cbc030110.php

[43] Yang, E.V. and Glaser, R. (2000) Stress-Induced Immunomodulation: Impact on 
Immune Defenses against Infectious Disease. Biomedicine \& Pharmacotherapy, 54, 245-250. https://doi.org/10.1016/S0753-3322(00)80066-9

[44] Cooper, A. and Jeitner, T. (2016) Central Role of Glutamate Metabolism in the Maintenance of Nitrogen Homeostasis in Normal and Hyperammonemic Brain. Biomolecules, 6, 16. https://doi.org/10.3390/biom6020016

[45] Zecca, L., et al. (2003) The Neuromelanin of Human Substantia Nigra: Structure, Synthesis and Molecular Behaviour. In: Horowski, R., et al., Eds., Advances in Research on Neurodegeneration. Journal of Neural Transmission. Supplementa, 65, 145-155. https://doi.org/10.1007/978-3-7091-0643-3_8

[46] Daw, N.D., Kakade, S. and Dayan, P. (2002) Opponent Interactions between Serotonin and Dopamine. Neural Networks, 15, 603-616.

https://doi.org/10.1016/S0893-6080(02)00052-7

[47] Davidson, R.J., Putnam, K.M. and Larson, C.L. (2000) Dysfunction in the Neural Circuitry of Emotion Regulation-A Possible Prelude to Violence. Science, 289, 591-594. https://doi.org/10.1126/science.289.5479.591

[48] Gatley, S.J., Volkow, N.D., Gifford, A.N., Fowler, J.S., Dewey, S.L., Ding, Y.S. and Logan, J. (1999) Dopamine-Transporter Occupancy after Intravenous Doses of Cocaine and Methylphenidate in Mice and Humans. Psychopharmacology, 146, 93-100. https://doi.org/10.1007/s002130051093

[49] Prentice, H., Gharibani, P.M., Ma, Z., Alexandrescu, A., Genova, R., Chen, P.C., Modi, J., Pan, C., Tao, R. and Wu, J.Y. (2017) Neuroprotective Functions through Inhibition of ER Stress by Taurine or Taurine Combination Treatments in a Rat Stroke Model. Advances in Experimental Medicine and Biology Taurine, 10, 193-205. https://doi.org/10.1007/978-94-024-1079-2_17

[50] Jia, F., Yue, M., Chandra, D., Keramidas, A., Goldstein, P.A., Homanics, G.E. and Harrison, N.L. (2008) Taurine Is a Potent Activator of Extrasynaptic GABAA Receptors in the Thalamus. Journal of Neuroscience, 28, 106-115. https://doi.org/10.1523/JNEUROSCI.3996-07.2008

[51] Wu, J.-Y. and Prentice, H. (2010) Role of Taurine in the Central Nervous System. Journal of Biomedical Science, 17, S1. https://doi.org/10.1186/1423-0127-17-S1-S1

[52] Brozoski, T.J., Caspary, D.M., Bauer, C.A. and Richardson, B.D. (2010) The Effect of Supplemental Dietary Taurine on Tinnitus and Auditory Discrimination in an Animal Model. Hearing Research, 270, 71-80. https://doi.org/10.1016/j.heares.2010.09.006

[53] Wada, H., Inagaki, N., Yamatodani, A. and Watanabe, T. (1991) Is the Histaminergic Neuron System a Regulatory Center for Whole-Brain Activity? Trends in Neurosciences, 14, 415-418. https://doi.org/10.1016/0166-2236(91)90034-R

[54] Kjaer, A., Knigge, U., Rouleau, A., Garbarg, M. and Warberg, J. (1994) Dehydration-Induced Release of Vasopressin Involves Activation of Hypothalamic Histaminergic Neurons. Endocrinology, 135, 675-681.

https://doi.org/10.1210/endo.135.2.8033816

[55] Knigge, U. and Warberg, J. (1991) The Role of Histamine in the Neuroendocrine Regulation of Pituitary Hormone Secretion. Acta Endocrinologica (Copenhagen), 124, 609-619. https://doi.org/10.1530/acta.0.1240609

[56] Zhong, Z., Wheeler, M.D., Li, X., Froh, M., Schemmer, P., Yin, M., Bunzendaul, H., Bradford, B. and Lemasters, J.J. (2003) L-Glycine: A Novel Antiinflammatory, Immunomodulatory, and Cytoprotective Agent. Current Opinion in Clinical Nutrition \& Metabolic Care, 6, 229-240. https://doi.org/10.1097/00075197-200303000-00013

[57] Baker, G.B., Bornstein, R.A., Rouget, A.C., Ashton, S.E., van Muyden, J.C. and 
Coutts, R.T. (1991) Phenylethylaminergic Mechanisms in Attention-Deficit Disorder. Biological Psychiatry, 29, 15-22. https://doi.org/10.1016/0006-3223(91)90207-3

[58] Butler, P.D., Susser, E.S., Brown, A.S., Kaufman, C.A. and Gorman, J.M. (2003) Prenatal Nutritional Deprivation as a Risk Factor in Schizophrenia: Preclinical Evidence. Neuropsychopharmacology, 11, 227-235.

[59] Irsfeld, M., Spadafore, M. and Prüß, B.M. (2013) $\beta$-Phenylethylamine, a Small Molecule with a Large Impact. WebmedCentral, 4, 4409.

[60] Ortego, L., Pelican, E., Callaba, L. and Marks, T. (2015) An Investigation of the Effects of MNRI Techniques on the Educational Performance of Kindergarten Students. In: Reflexes: Portal to Neurodevelopment and Learning, a Collective Work, SMEI, Orlando, 142-156.

[61] Akhmatova, N., Masgutova, S., Shubina, I., Akhmatov, E., Khomenkov, V., Sorokina, E., Korovkina, E. and Kostinov, M. (2015) Immunological Effects of Masgutova Neurosensorimotor Reflex Integration in Children with Recurrent Obstructive Bronchitis. International Journal of Neurorehabilitation, 2, 166-175.

[62] Delahanty, D.L., Nugent, N.R., Christopher, N.C. and Walsh, M. (2005) Initial Urinary Epinephrine and Cortisol Levels Predict Acute PTSD Symptoms in Child Trauma Victims. Psychoneuroendocrinology, 30, 121-128. https://doi.org/10.1016/j.psyneuen.2004.06.004

[63] Kim, K.S., Oh, D., Kim, J.Y., et al. (2012) Taurine Ameliorates Hyperglycemia and Dyslipidemia by Reducing Insulin Resistance and Leptin Level in Otsuka Long-Evans Tokushima Fatty (OLETF) Rats with Long-Term Diabetes. Experimental \& Molecular Medicine, 44, 665-673. https://doi.org/10.3858/emm.2012.44.11.075

[64] Austin, M.V. (2018) ADHD: Attention Deficit Hyperactivity Disorder. Neurotransmitter Changes with ADHD.

https://www.gulfbend.org/poc/view_doc.php?type=doc\&id=13861\&cn=3

[65] Wilcox, K.S., Buchhalter, J. and Dichter, M.A. (1994) Properties of Inhibitory and Excitatory Synapses between Hippocampal Neurons in Very Low Density Cultures. Synapse, 18, 128-151. https://doi.org/10.1002/syn.890180206

[66] Fletcher, E.V., Simon, C.M., Pagiazitis, J.G., Chalif, J.I., Vukojicic, A., et al. (2017) Reduced Sensory Synaptic Excitation Impairs Motor Neuron Function via Kv2.1 in Spinal Muscular Atrophy. Nature Neuroscience, 20, 905-916. https://doi.org/10.1038/nn.4561

[67] https://opentextbc.ca/anatomyandphysiology

[68] Miller, A.H., Haroon, E., Raison, C.L. and Felger, J.C. (2013) Cytokine Targets in the Brain: Impact on Neurotransmitters and Neurocircuits. Depress Anxiety, 30, 297-306. https://doi.org/10.1002/da.22084

[69] Harris, K.D., Weiss, M. and Zahavi, A. (2014) Why Are Neurotransmitters Neurotoxic? An Evolutionary Perspective. F1000Research, 3, 179. https://doi.org/10.12688/f1000research.4828.2

[70] Young, S.N. and Leyton, M. (2002) The Role of Serotonin in Human Mood and Social Interaction. Insight from Altered Tryptophan Levels. Pharmacology Biochemistry and Behavior, 71, 857-865. https://doi.org/10.1016/S0091-3057(01)00670-0

[71] Institute of Medicine (US) Forum on Neuroscience and Nervous System Disorders (2011) Glutamate-Related Biomarkers in Drug Development for Disorders of the Nervous System: Workshop Summary. National Academies Press, Washington DC. 
https://www.ncbi.nlm.nih.gov/books/NBK62187

[72] https://www.medicalnewstoday.com/kc/serotonin-facts-232248

[73] Drevets, W.C., Price, J.L. and Furey, M.L. (2008) Brain Structural and Functional Abnormalities in Mood Disorders: Implications for Neurocircuitry Models of Depression. Brain Structure \& Function, 213, 93-118. https://doi.org/10.1007/s00429-008-0189-x

[74] Schaumann, T., Kraus, D., Winter, J., Wolf, M., Deschner, J. and Jäger, A. (2013) Potential Immune Modularly Role of Glycine in Oral Gingival Inflammation. Clinical \& Developmental Immunology, 2013, Article ID: 808367. https://doi.org/10.1155/2013/808367

[75] Akhmatova, N., Masgutova, S., Lebedinskaya, O., Akhmatov, E. and Shubina, I. (2015) Immunological Efficiency of MNRI Program at Treatment of Respiratory Diseases. 11 th Congress of the Latin American Association of Immunology, Medellin, 13-16 October 2015. https://doi.org/10.3389/conf.fimmu.2015.05.00072

[76] Tank, A.W. and Wong, D.L. (2015) Peripheral and Central Effects of Circulating Catecholamines. Comprehensive Physiology, 5, 1-15.

https://doi.org/10.1002/cphy.c140007

[77] Hough, L.B. (1999) Histamine Actions in the Central Nervous System. In: Basic Neurochemistry: Molecular, Cellular and Medical Aspects, 6th Edition, Lippincott-Raven, Philadelphia. http://ncbi.nlm.nih.gov/books/NBK28245

[78] Haas, H.L., Sergeeva, O.A. and Selbach, O. (2008/2012) Histamine in the Nervous System. Physiological Reviews, 88, 1183-1241. https://doi.org/10.1152/physrev.00043.2007

[79] Strac, D.S., Pivac, N., Smolders, I.J., Fogel, W.A., Deurwaerdere, P.D. and Giovanni, G.D. (2016) Monoaminergic Mechanisms in Epilepsy May Offer Innovative Therapeutic Opportunity for Monoaminergic Multi-Target Drugs. Frontiers in Neuroscience, 10, 492. https://doi.org/10.3389/fnins.2016.00492

[80] Schaffer, S. and Kim, H.W. (2018) Effects and Mechanisms of Taurine as a Therapeutic Agent. Biomolecules \& Therapeutics (Seoul), 26, 225-241. https://doi.org/10.4062/biomolther.2017.251

[81] Oja, S.S. and Saransaari, P. (2017) Significance of Taurine in the Brain. Advances in Experimental Medicine and Biology, 975, 89-94. https://doi.org/10.1007/978-94-024-1079-2_8

[82] Alaniz-Palacios, A. and Martínez-Torres, A. (2017) Antagonistic Effect of Dopamine Structural Analogues on Human GABAp1 Receptor. Scientific Reports, 7, Article No. 17385. http://www.nature.com/articles/s41598-017-17530-8 https://doi.org/10.1038/s41598-017-17530-8

[83] Kusaga, A. (2002) Decreased Beta-Phenylethylamine in Urine of Children with Attention Deficit Hyperactivity Disorder and Autistic Disorder. Brain and Development, 34, 243-248.

[84] Sarkar, A., Lehto, S.M., Harty, S., Dinan, T.G., Cryan, J.F. and Burnet, P. (2016) Psychobiotics and the Manipulation of Bacteria-Gut-Brain Signals. Trends in Neurosciences, 39, 763-781. https://doi.org/10.1016/j.tins.2016.09.002 